\title{
Sensitivity of thermal infrared nadir instruments to the chemical and microphysical properties of UTLS secondary sulfate aerosols
}

\author{
P. Sellitto and B. Legras
}

Laboratoire de Météorologie Dynamique (LMD), CNRS-UMR8539, Institut Pierre Simon Laplace, École Normale Supérieure, École Polytechnique, Université Pierre et Marie Curie, Paris, France

Correspondence to: P. Sellitto (psellitto@1md.ens.fr)

Received: 28 June 2015 - Published in Atmos. Meas. Tech. Discuss.: 10 August 2015

Revised: 19 November 2015 - Accepted: 18 December 2015 - Published: 18 January 2016

\begin{abstract}
Monitoring upper-tropospheric-lowerstratospheric (UTLS) secondary sulfate aerosols and their chemical and microphysical properties from satellite nadir observations is crucial to better understand their formation and evolution processes and then to estimate their impact on UTLS chemistry, and on regional and global radiative balance. Here we present a study aimed at the evaluation of the sensitivity of thermal infrared (TIR) satellite nadir observations to the chemical composition and the size distribution of idealised UTLS sulfate aerosol layers. The extinction properties of sulfuric acid/water droplets, for different sulfuric acid mixing ratios and temperatures, are systematically analysed. The extinction coefficients are derived by means of a Mie code, using refractive indices taken from the GEISA (Gestion et Étude des Informations Spectroscopiques Atmosphériques: Management and Study of Spectroscopic Information) spectroscopic database and log-normal size distributions with different effective radii and number concentrations. IASI (Infrared Atmospheric Sounding Interferometer) pseudo-observations are generated using forward radiative transfer calculations performed with the 4A (Automatized Atmospheric Absorption Atlas) radiative transfer model, to estimate the impact of the extinction of idealised aerosol layers, at typical UTLS conditions, on the brightness temperature spectra observed by this satellite instrument. We found a marked and typical spectral signature of these aerosol layers between 700 and $1200 \mathrm{~cm}^{-1}$, due to the absorption bands of the sulfate and bisulfate ions and the undissociated sulfuric acid, with the main absorption peaks at 1170 and $905 \mathrm{~cm}^{-1}$. The dependence of the aerosol spectral signature to the sulfuric acid mixing ratio, and effective number concentration and radius, as well as the
\end{abstract}

role of interfering parameters like the ozone, sulfur dioxide, carbon dioxide and ash absorption, and temperature and water vapour profile uncertainties, are analysed and critically discussed. The information content (degrees of freedom and retrieval uncertainties) of synthetic satellite observations is estimated for different instrumental configurations. High spectral resolution (IASI-like pseudo-observations) and broadband spectral features (Moderate Resolution Imaging Spectroradiometer (MODIS) and Spinning Enhanced Visible and InfraRed Imager (SEVIRI)-like pseudo-observations) approaches are proposed and discussed.

\section{Introduction}

Secondary sulfate aerosols are sulfate-containing aqueous solution droplets, generally of submicron size, produced from gas-to-particle conversion processes involving sulfurcontaining gaseous precursors (Hamill et al., 1997). They are one of the predominant types of aerosols in the upper troposphere/lower stratosphere (UTLS) (SPARC, 2006; Sheng et al., 2015; Yu et al., 2015) and can have an important impact on the atmospheric radiative transfer and climate (see e.g. Robock and Oppenheimer, 2003), cirrus formation and their optical properties (see e.g. Gettelman et al., 2012) and chemistry in the UTLS (see e.g. von Glasow et al., 2009). Monitoring their chemical composition, i.e. the mixing ratio of sulfates in the aqueous solution, and their microphysical properties, i.e. the size distribution parameters, is fundamental to better understand the processes of formation and their impacts on UTLS chemistry and radiative transfer. From a satellite perspective, limb-viewing and occultation 
UV/VIS/NIR (ultraviolet, visible, near-infrared) and TIR (thermal infrared) instruments, e.g. the Stratospheric Aerosol and Gas Experiment (SAGE) II and III (e.g. Thomason et al., 1997; Bauman et al., 2003), the Improved Stratospheric and Mesospheric Sounder (ISAMS) (e.g. Grainger et al., 1993; Echle et al., 1998), the Atmospheric Trace Molecule Spectroscopy (ATMOS) (e.g. Eldering et al., 2004), the Optical Spectrograph and Infrared Imager System (OSIRIS) (e.g. Bourassa et al., 2010) and Atmospheric Chemistry Experiment (ACE)-Fourier Transform Spectrometer (FTS) (e.g. Doeringer et al., 2012) have been used to derive vertical profiles of UTLS sulfate aerosol absorption, especially during strong volcanic eruptions. These observations have allowed the identification of the perturbation of the UTLS aerosol layer produced by stronger volcanic eruptions. The retrieval of some parameters has also been attempted, like sulfate mass or density (e.g. Yu and Rose, 2000; Echle et al., 1998), effective radius (e.g. Lambert et al., 1997; Yu and Rose, 2000; Doeringer et al., 2012; Bauman et al., 2003) and sulfate aerosol composition (e.g. Lambert et al., 1997; Echle et al., 1998; Doeringer et al., 2012). Some of these works rely on strong assumptions. For example, Yu and Rose (2000) and Bauman et al. (2003) used a fixed sulfate mixing ratio and temperature of the aerosol layer (and so a fixed refractive index) and Echle et al. (1998) and Yu and Rose (2000) considered sulfate aerosols as purely absorbing.

In addition, limb and occultation observations are not well adapted to monitor the processes of formation and evolution of the aerosol population due to the low horizontal resolution and the scarce distribution of observations. Routine nadir measurements are more adapted to monitor sulfate aerosols properties from the regional to the global scale, to constrain processes and to estimate the global impact of sulfate aerosol production and evolution, due to their extended spatial coverage and higher spatial resolution. Nadir satellite observations in the solar spectral range (UV/VIS/NIR) are insensitive to the chemical composition of aerosols, while they can provide partial information on their size distribution, via the fine-tocoarse aerosol optical depth ratio (Kaufman et al., 2005; Remer et al., 2005). Thermal infrared (TIR) observations are sensitive to the chemical composition of the aerosols due to the strong spectral variations of the imaginary part of the refractive index in this band and, correspondingly, of the absorption, as a function of the composition (e.g. Clarisse et al., 2013). Unfortunately, the exploitation of nadir TIR observations for sulfate aerosol layer monitoring consists today only of a semi-quantitative detection (Clarisse et al., 2013), as nadir observations are generally regarded as weakly sensitive to the relatively small and diluted (in terms of their number concentration) sulfate aerosol droplets. As a consequence, despite their importance, satellite observation of sulfate aerosols in the UTLS at the regional scale, and their properties, is limited.

In this work, we present an analysis of the sensitivity of the satellite nadir TIR observations to secondary sulfate aerosols in the UTLS and their chemical and microphysical properties. The main target of this paper is to link the optical characterisation of sulfate solutions, as available from the published spectroscopic laboratory measurements of e.g. Biermann et al. (2000), to the empiric observation of aerosol signatures in favourable natural contexts, e.g. for the production of volcanically enhanced sulfates in the UTLS. Indeed, a peculiar aerosol signature (increasing absorption between about 700 and $1300 \mathrm{~cm}^{-1}$ ) has been observed in the past in those conditions, e.g. by Clarisse et al. (2013) for the eruption of the Sarychev volcano, by Baran et al. (1993); Grainger et al. (1993); Ackerman and Strabala (1994) for the eruption of the Pinatubo volcano and by Karagulian et al. (2010) for the eruption of the Kasatochi volcano. These signatures have been attributed to the secondary sulfate aerosols formed in the volcanic plume, without linking them to the specific spectroscopic features of the different sulfur-containing species (e.g. undissociated sulfuric acid molecules, sulfate and bisulfate ions) contained in the droplets and their chemical and microphysical characterisation. Establishing such a link will improve our understanding of the radiative properties of these aerosol layers and is a prerequisite for an optimal retrieval of their properties from satellite data. To do so, the extinction properties of sulfuric acid/water droplets, for different sulfuric acid mixing ratios and temperatures, are systematically analysed. The extinction coefficients are derived by means of a Mie code, using refractive indices taken from the GEISA (Gestion et Étude des Informations Spectroscopiques Atmosphériques: Management and Study of Spectroscopic Information) spectroscopic database and log-normal size distributions with different effective radii and number concentrations. IASI (Infrared Atmospheric Sounding Interferometer) pseudo-observations are generated using forward radiative transfer calculations performed with the $4 \mathrm{~A}(\mathrm{Au}-$ tomatized Atmospheric Absorption Atlas) radiative transfer model, to estimate the impact of the absorption of idealised aerosol layers, at typical UTLS conditions, on the brightness temperature (BT) spectra observed by simulated satellite instruments.

The paper is organised as follows: in Sect. 2 we introduce the data and methods used in our study. In Sect. 3 we discuss the spectral absorption of the sulfate aerosol layer, and the dependence of the absorption on the chemical and microphysical properties of the layer. The IASI pseudoobservations obtained using these aerosol optical characterisations are discussed in Sect. 4, and the UTLS sulfate aerosol BT signature is isolated and analysed with respect to the chemical and microphysical properties of the layer. The role of interfering parameters, e.g. the uncertainties of the temperature, and water vapour and ozone concentration profiles, as well as the absorption by other volcanic species as $\mathrm{SO}_{2}, \mathrm{CO}_{2}$ and ash, are discussed in Sect. 5. The information content of pseudo-observations with different simulated instrumental configurations is discussed in Sect. 6. Conclusions are drawn in Sect. 7. 


\section{Data and methods}

To analyse the sensitivity of nadir satellite observations in the TIR spectral region, we have generated a set of IASI pseudo-observations with the Automatized Atmospheric Absorption Atlas OPerational (4A/OP) radiative transfer model, (see e.g. Scott and Chedin, 1981). 4A/OP is a fast and accurate line-by-line radiative transfer model, developed by the Laboratoire de Météorologie Dynamique and the NOVELTIS company (http://www.noveltis.com/) with the support of the CNES (Centre National d'Études Spatiales), to simulate the radiative transfer in planetary atmospheres, with a particular focus on the IR spectral region. In Tjemkes et al. (2003) 4A/OP simulations, as well as simulations from nine other radiative transfer models, were compared to IR high spectral resolution observations (aircraft observations with the High-resolution Interferometer Sounder and the Airborne Research Interferometer Evaluation System) and found capable of reproducing the observations to within the observation noise. 4A/OP has been used in support of the IASI missions (Jacquinet-Husson et al., 2003). Please refer to the website http://4aop.noveltis.com/ for more details of 4A/OP.

In the present work, IASI observations are simulated by means of the observation geometry, the instrument spectral response function (ISRF) and the radiometric noise. Typical nadir observations have been considered, with zero viewing zenith angle. We have simulated radiances in the range $700.0-1300.0 \mathrm{~cm}^{-1}$, with a spectral resolution of $0.25 \mathrm{~cm}^{-1}$ before apodization $\left(0.50 \mathrm{~cm}^{-1}\right.$ apodized spectral resolution), a spectral sampling of $0.25 \mathrm{~cm}^{-1}$ and a Gaussian ISRF. The radiometric noise is set at a noise equivalent brightness temperature of $0.25 \mathrm{~K}$. These parameters are implemented into the standard distribution of $4 \mathrm{~A} / \mathrm{OP}$, and based on IASI preparatory studies (see e.g. Tournier et al., 2002).

A baseline 4A/OP run, i.e. a run with no sulfate aerosols, is first performed to compare with different configurations of the UTLS sulfate aerosol layer, i.e. with different chemical and microphysical properties. Then different runs with varying $\mathrm{H}_{2} \mathrm{SO}_{4}$ mixing ratios and aerosol size distributions are performed. For all these simulations, a typical tropical atmosphere is considered in terms of temperature, pressure and trace gas vertical profiles. The altitude of the sulfate aerosol layer is fixed at about $150 \mathrm{hPa}$. $4 \mathrm{~A} / \mathrm{OP}$ is capable of simulating aerosol scattering and absorption by means of the DISORT (Discrete Ordinate Radiative Transfer) scheme, using the extinction (absorption plus scattering) coefficient, the single scattering albedo and the asymmetry parameter as optical inputs. These optical parameters for the different simulated sulfate aerosol layers are obtained with IDL (Interactive Data Language, http://www.exelisvis.com/ProductsServices/ IDL.aspx) Mie scattering routines of the Earth Observation Data Group of the Department of Physics of Oxford University. Starting from the refractive index and the size distribution of the aerosol layer, the Mie theory allows the calculation of the extinction, scattering and absorption coefficients, as well as derived quantities like the single scattering albedo, and the angular distribution of the radiation fields (by means of the phase function), which can be represented by the integral asymmetry parameter (van de Hulst, 1957). It is worth mentioning that using Legendre moments would be a better approximation of the phase function, when scattering processes are more important.

In this work we assume that sulfate aerosols are binary systems of $\mathrm{H}_{2} \mathrm{SO}_{4} / \mathrm{H}_{2} \mathrm{O}$ solution droplets, with varying $\mathrm{H}_{2} \mathrm{SO}_{4}$ mixing ratios. Ternary $\mathrm{HNO}_{3} / \mathrm{H}_{2} \mathrm{SO}_{4} / \mathrm{H}_{2} \mathrm{O}$ solutions, which are important for the formation of nitric acid hydrates in polar stratospheric clouds (Knopf et al., 2002), are excluded from this study. We have used temperature-dependent refractive indices for different mixing ratios of the binary system $\mathrm{H}_{2} \mathrm{SO}_{4} / \mathrm{H}_{2} \mathrm{O}$ from the laboratory study of Biermann et al. (2000). These data are available from the GEISA database (Jacquinet-Husson et al., 2008). Refractive indices are available for a wide array of temperatures, from 183 to $293 \mathrm{~K}$, and $\mathrm{H}_{2} \mathrm{SO}_{4}$ mixing ratios (in mass, i.e. the ratio of the $\mathrm{H}_{2} \mathrm{SO}_{4}$ mass to the total mass of the droplets) ranging from 10 to $80 \%$, so covering tropospheric and stratospheric conditions. These refractive indices are measured in the region 500.0 $5000.0 \mathrm{~cm}^{-1}$, where major features of the absorption spectra of sulfate droplets-radiation can be found, i.e. the $\mathrm{OH}$ stretching region $\left(3200-3500 \mathrm{~cm}^{-1}\right)$, bisulfate ion absorption $\left(1341,1030,1050,885\right.$ and $\left.593 \mathrm{~cm}^{-1}\right)$ and sulfate ion absorption (1104 and $\left.613 \mathrm{~cm}^{-1}\right)$. For higher concentrations, features of the undissolved $\mathrm{H}_{2} \mathrm{SO}_{4}$ molecules (absorption at 1370, 1170, 965, 905 and $564 \mathrm{~cm}^{-1}$ ) appear as well. Please refer to Biermann et al. (2000) for more details on this data set and to e.g. Miller et al. (2005) and Boer et al. (2007) for a detailed description of the spectroscopic absorption vibration modes for the sulfate and bisulfate ions, and the sulfuric acid molecule.

The size distributions for our simulated layers (i.e. a function $n(r)$ defined so that $n(r) \mathrm{d} r$ is the number of particles per unit volume, with a radius between $r$ and $r+\mathrm{d} r$ ) are modelled as log-normal distributions:

$n(r)=\frac{N_{0}}{r \ln \sigma_{r} \sqrt{2 \pi}} e^{-\frac{1}{2}\left(\frac{\ln (r / r \mathrm{~m})}{\ln \sigma_{r}}\right)^{2}}$.

In Eq. (1), $N_{0}$ is the total number concentration (in particles $\left.\mathrm{cm}^{-3}\right), r_{\mathrm{m}}$ is the mean radius and $\ln \sigma_{r}$ is the unitless standard deviation of $\ln \left(r / r_{\mathrm{m}}\right)$. For our simulations, we fixed $\sigma_{r}$ to 1.86 (a typical value; see e.g. SPARC, 2006) and we varied $N_{0}$ and $r_{\mathrm{m}}$, to study the impact of different number concentrations and mean size on the absorption properties of the sulfate aerosol layers. We simulate layers with $N_{0}=8$, $9,10,12,15,20,25$ and 30 particles $\mathrm{cm}^{-3}$, and $r_{\mathrm{m}}=0.06$, $0.07,0.08,0.1,0.15,0.2,0.3$ and $0.4 \mu \mathrm{m}$. Here we recall that a typical UTLS sulfate aerosol layer in background conditions, i.e. without any perturbation from emissions of sulfur compounds from natural (volcanic explosive eruptions) or anthropic (severe UTLS pollution) sources, can be repre- 
Table 1. Total number concentrations and effective number concentrations used in the present work.

\begin{tabular}{rr}
\hline $\begin{array}{r}\text { Number concentration } \\
\left(\text { particles } \mathrm{cm}^{-3} \text { ) }\right.\end{array}$ & $\begin{array}{r}\text { Effective number concentration } \\
\text { (particles } \mathrm{cm}^{-3} \text { ) }\end{array}$ \\
\hline 8 & 2.52 \\
9 & 2.83 \\
10 & 3.15 \\
12 & 3.78 \\
15 & 4.72 \\
20 & 6.83 \\
25 & 7.87 \\
30 & 9.45 \\
\hline
\end{tabular}

sented by a log-normal distribution with $N_{0}$ of a few particles $\mathrm{cm}^{-3}$ and a $r_{\mathrm{m}}$ lower than $0.1 \mu \mathrm{m}$, while a volcanically perturbed layer can be represented by a log-normal distribution with $N_{0}$ of a few tens particles $\mathrm{cm}^{-3}$ and a $r_{\mathrm{m}}$ higher than $0.2 \mu \mathrm{m}$ (SPARC, 2006). Thus, our database can represent several naturally occurring conditions. It must be noted here that multi-modal log-normal distributions have also been observed, especially in volcanically perturbed situations (see e.g. Deshler et al., 2003), but are not simulated in the present study. We plan in the future to extend our simulations to multi-modal log-normal size distributions.

From $\mathrm{H}_{2} \mathrm{SO}_{4}$ concentration and aerosol size distribution, other parameters can be derived, which are useful metrics for remote sensing measurements. It is often convenient to express the size distribution with compact parameters, like the effective radius $r_{\mathrm{e}}$ and the effective number concentration $N_{\mathrm{e}}$. The effective radius is directly linked to the extinction properties of the layer. These two quantities are defined as follows (see e.g. Korolev et al., 1999):

$r_{\mathrm{e}}=\frac{\int r^{3} n(r) \mathrm{d} r}{\int r^{2} n(r) \mathrm{d} r}$

$N_{\mathrm{e}}=\frac{\left(\int r^{2} n(r) \mathrm{d} r\right)^{3}}{\left(\int r^{3} n(r) \mathrm{d} r\right)^{2}}$.

Because $\sigma_{r}$ is fixed in our simulations, it follows that

$r_{\mathrm{e}}=r_{\mathrm{m}} e^{2.5 \ln ^{2} \sigma_{r}}=2.619 r_{\mathrm{m}}$

$N_{\mathrm{e}}=N_{0} e^{-3.0 \ln ^{2} \sigma_{r}}=0.315 N_{0}$.

The two quantities are defined in such a way that

$N_{\mathrm{e}} r_{\mathrm{e}}^{2}=N_{0} r_{\text {surf }}^{2}$

where $r_{\text {surf }}=\frac{1}{N_{0}} \int r^{2} n(r) \mathrm{d} r$ is the mean surface area of the aerosol layer. Please find in Tables 1 and 2 the total number concentrations and the mean radii used in this work, with the corresponding effective radii and number concentrations.
Table 2. Mean radii and effective radii used in the present work.

\begin{tabular}{rr}
\hline Mean radius $(\mu \mathrm{m})$ & Effective radius $(\mu \mathrm{m})$ \\
\hline 0.06 & 0.16 \\
0.07 & 0.18 \\
0.08 & 0.21 \\
0.10 & 0.26 \\
0.15 & 0.39 \\
0.20 & 0.52 \\
0.30 & 0.79 \\
0.40 & 1.05 \\
\hline
\end{tabular}

Then, from these two quantities and the sulfate aerosol density, the effective mass volume concentration (in $\mathrm{g} \mathrm{m}^{-3}$ ) can be defined as follows:

$M_{\mathrm{e}}=\frac{4}{3} \pi \rho(c) r_{\mathrm{e}}^{3} N_{\mathrm{e}}$.

In Eq. (7), $\rho(c)$ is the density of the sulfate aerosols (a function of the $\mathrm{H}_{2} \mathrm{SO}_{4}$ concentration), which has been considered as fixed in a given aerosol layer. The effective mass volume concentration can then be used to calculate the total mass (in $\mathrm{g}$, by multiplying by the volume occupied by the aerosols) or the effective columnar abundance (in $\mathrm{g} \mathrm{m}^{-2}$ by multiplying by the vertical altitude interval occupied by the aerosols). This latter quantity,

$M_{\mathrm{col}}=M_{\mathrm{e}} \cdot \Delta z$,

is linked to the total absorption due to the presence of sulfate aerosols and is considered in the following discussions.

The extinction coefficient $\beta_{\text {ext }}$, discussed in the following sections, can be expressed as follows:

$$
\begin{aligned}
\beta_{\text {ext }}\left(c, r_{\mathrm{e}}, N_{\mathrm{e}}, v\right) & =\int \pi r^{2} Q_{\mathrm{ext}}(m(c), r, v) n(r) \mathrm{d} r \\
& =\int \pi r^{2} Q_{\mathrm{ext}}(m(c), r, v) \\
& \frac{N_{0}}{r \ln \sigma_{r} \sqrt{2 \pi}} e^{-\frac{1}{2}\left(\frac{\ln \left(r / r_{\mathrm{m}}\right)}{\ln \sigma_{r}}\right)^{2}} \mathrm{~d} r,
\end{aligned}
$$

where $Q_{\text {ext }}(m(c), r, v)$ is the single particle extinction efficiency factor from Mie theory, $m$ is the complex refractive index, which is a function of the $\mathrm{H}_{2} \mathrm{SO}_{4}$ mixing ratio $(c)$, and $n(r)$ is the considered log-normal size distribution. The mean radius and the total number concentration are linked to the effective radius and number concentration by Eqs. (4) and (5). The dependence of the $\beta_{\text {ext }}$ spectra on $c$ is transferred from $Q_{\text {ext }}$, and the dependence on $N_{\mathrm{e}}$ and $r_{\mathrm{e}}$ is transferred from $n(r)$. From the Eq. (9), it follows that the extinction coefficient can be separated in two factors:

$\beta_{\text {ext }}\left(c, r_{\mathrm{e}}, N_{\mathrm{e}}, v\right)=N_{\mathrm{e}} \mathrm{F}\left(c, r_{\mathrm{e}}, v\right)$,

where the function $F\left(c, r_{\mathrm{e}}, v\right)$ does not depend on the effective number concentration $N_{\mathrm{e}}$. 


\section{Optical characterisation of the sulfate aerosol layers: dependence of the extinction coefficient on chemical and microphysical properties}

\subsection{Sulfate aerosol absorption and scattering}

We first analyse the spectral extinction coefficient for different chemical and microphysical properties of the sulfate aerosols layer. Previous studies on the retrieval of sulfate aerosols have neglected the scattering component of the extinction coefficient in the TIR spectral region; see e.g. Echle et al. (1998) and Yu and Rose (2000). In Fig. 1 we show the single scattering albedo (the ratio of the scattering and the extinction coefficient) of sulfate layers with two different $\mathrm{H}_{2} \mathrm{SO}_{4}$ mixing ratios (64 and $75 \%$ ) and two typical size distributions: a background, volcanically quiescent aerosol layer $\left(N_{0}=9 \mathrm{~cm}^{-3}, r_{\mathrm{m}}=0.07 \mu \mathrm{m}, \sigma_{\mathrm{m}}=1.86\right)$, and a moderately perturbed volcanic aerosol layer $\left(N_{0}=\right.$ $30 \mathrm{~cm}^{-3}, r_{\mathrm{m}}=0.2 \mu \mathrm{m}, \sigma_{\mathrm{m}}=1.86$ ). In volcanically perturbed conditions, the number concentration $N_{0}$ is higher due to the enhanced formation of new particles from sulfur dioxide emissions and the mean radius $r_{\mathrm{m}}$ is bigger due to the enhanced coagulation of droplets in denser environments (see e.g. McCormick et al., 1995; Deshler et al., 2003). In Fig. 1, as well as in the other figures of this section, the spectral discretization (available wavenumbers) originates from the spectral discretization of the refractive indices in the database of Biermann et al. (2000). While the absorption dominates the extinction in the TIR spectral region, the scattering component has increasing values for bigger particles and can reach values up to about $20 \%$ in volcanic conditions. This result suggests that the scattering component of the extinction, even if relatively small with respect to the absorption, cannot be neglected in volcanically perturbed conditions. Correspondingly, in the following sections we study the extinction coefficient of the layer. The parameters of the aerosol layer are the $\mathrm{H}_{2} \mathrm{SO}_{4}$ mixing ratio, the temperature and the size distribution.

\subsection{Dependence of the extinction coefficient on the $\mathrm{H}_{2} \mathrm{SO}_{4}$ mixing ratio and the temperature}

To study how the extinction of the layer varies with respect to the $\mathrm{H}_{2} \mathrm{SO}_{4}$ mixing ratio and the temperature, we use the tabulated combinations of mixing ratios and temperatures in GEISA, as described in Sect. 2, and we fix the size distribution. The whole set of temperature/mixing ratio combinations, i.e. not constrained to UTLS conditions, is analysed in the present section. This has been done to have a more complete view of this dependency. We consider the two size distributions, background and volcanic, introduced in Sect. 3.1. As said before, the absorption dominates over the scattering and so the extinction coefficient discussed in the following is mostly defined by the sulfate absorption spectral features,

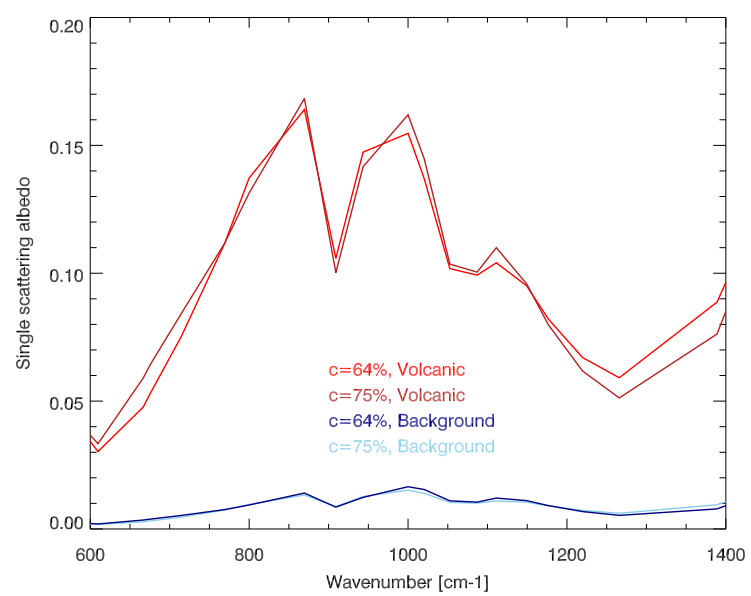

Figure 1. Spectral single scattering albedo, in the spectral range $600-1400 \mathrm{~cm}^{-1}$, for sulfate aerosol layers with different $\mathrm{H}_{2} \mathrm{SO}_{4}$ mixing ratios (64 and $75 \%$, at $213-215 \mathrm{~K}$ ), for typical background size distribution (dark and light blue lines) and for a moderate volcanically perturbed size distribution (dark and light red lines). See the text for further details.

except for a small correction for layers with bigger particles (volcanic conditions, see Fig. 1 and inherent text).

Figure 2 shows the extinction coefficient in the range 600 to $1400 \mathrm{~cm}^{-1}$ for sulfate aerosol layers at temperatures of 293 and $213 \mathrm{~K}$, and different $\mathrm{H}_{2} \mathrm{SO}_{4}$ mixing ratios, depending on the availability of mixing ratio/temperature combinations in the data set. The complete data set, for all available temperatures in the interval $188-293 \mathrm{~K}$ can be found in Figs.S 1 and S2 of the Supplement. In all cases, the extinction in volcanically perturbed conditions is at least 50 times larger than in non-volcanic conditions, as a result of more $\left(N_{0}=20\right.$ vs. $\left.8 \mathrm{~cm}^{-3}\right)$ and bigger $\left(r_{\mathrm{m}}=0.3\right.$ vs. $\left.0.06 \mu \mathrm{m}\right)$ particles. This suggests a strong sensitivity of the sulfate aerosol extinction to the size distribution, which is more thoroughly discussed in Sect. 3.3. The $\mathrm{H}_{2} \mathrm{SO}_{4}$ mixing ratio is a relatively sensitive parameter as well, as the variability of the extinction coefficient with respect to this parameter is over a factor 3 to 5 for each given temperature. The sulfate absorption region is located in this spectral range and is clearly visible. A minimum extinction occurs at $650-800 \mathrm{~cm}^{-1}$. Then, from 900 to $1300 \mathrm{~cm}^{-1}$ the absorption bands of the sulfate ion $\left(\nu_{3} \mathrm{SO}_{4}^{2-}\right.$ asymmetric stretch band, centred at about $1104 \mathrm{~cm}^{-1}$ ), the bisulfate ion $\left(v_{1} \mathrm{SO}_{3}^{-}\right.$symmetric stretch band, centred between 1030 and $1050 \mathrm{~cm}^{-1}$ ) and of the undissociated sulfuric acid molecule (combination of bend and stretch of different groups, with absorption peaks centred at 905, 965 and $1170 \mathrm{~cm}^{-1}$ ) dominate, generating a general increase with wavelength of the absorption (and then of the extinction) in this spectral region, with additional absorption features at smaller spectral resolution. At mixing ratios larger than $50 \%$ and at all temperatures, a maximum of the $\mathrm{H}_{2} \mathrm{SO}_{4}$ molecule absorption appears at $1170 \mathrm{~cm}^{-1}$ that is quite elevated; for 

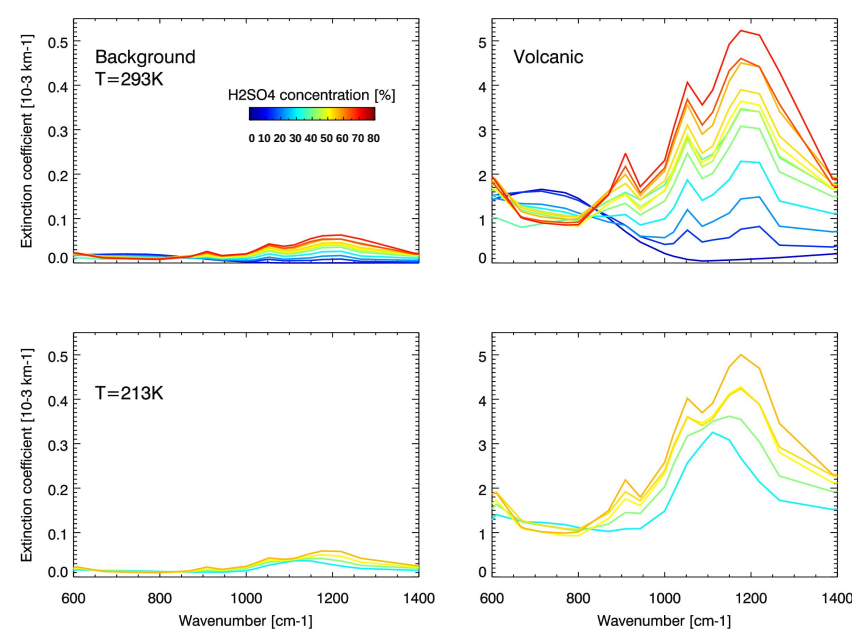

Figure 2. Spectral extinction coefficients for sulfate aerosol layers with different $\mathrm{H}_{2} \mathrm{SO}_{4}$ mixing ratios, from 0 to $80 \%$ as indicated by the colour bar, and temperatures of $293 \mathrm{~K}$ (upper row) and $213 \mathrm{~K}$ (bottom row). Different mixing ratio/temperature combinations are shown, depending on the availability in the refractive indices data set of Biermann et al. (2000). The extinction coefficients are shown for a typical background size distribution (left column) and for a moderate volcanically perturbed size distribution (right column). See the text for further details.

smaller mixing ratios and lower temperatures, the sulfate ion absorption feature at $1104 \mathrm{~cm}^{-1}$ dominates, while the impact of the $\mathrm{H}_{2} \mathrm{SO}_{4}$ molecular absorption at $1170 \mathrm{~cm}^{-1}$ is less marked. Two further peaks can be found at about $905 \mathrm{~cm}^{-1}$ (sulfuric acid molecular band) and $1050 \mathrm{~cm}^{-1}$ (bisulfate ion bands). In general, the $\mathrm{H}_{2} \mathrm{SO}_{4}$ absorption bands are more important for concentrated solutions $(>60 \%)$, as Giguère and Savoie (1960) first noticed and attributed to different autodissociation equilibria occurring at such higher concentrations. For more diluted solutions, the dependence of the absorption spectra on temperature is due to the dependence of the dissociation constant of the sulfate/bisulfate system on temperature (Biermann et al., 2000). Except for this effect, the temperature seems a much less important factor than the mixing ratio, to determine the absorption properties of the aerosol layer, especially in real world UTLS conditions $\left(\mathrm{H}_{2} \mathrm{SO}_{4}\right.$ mixing ratios greater than $60 \%$, temperatures smaller than $220 \mathrm{~K}$ SPARC, 2006).

A general increasing absorption by UTLS secondary sulfate aerosols in the range $700-1300 \mathrm{~cm}^{-1}$ has been indeed observed in the past by satellite limb observations, due to the Mount Pinatubo eruption of 1991 (Grainger et al., 1993). The two absorption peaks at 905 and $1170 \mathrm{~cm}^{-1}$ have also been observed by MIPAS-B (Michelson Interferometer for Passive Atmospheric Sounding - Balloon-borne version) limb observations at altitudes between 11 and $16 \mathrm{~km}$ for the same volcanic event (see the spectra of Fig. 3 in Echle et al., 1998, which have shapes and absolute values comparable to those of Fig. 2 of the present paper, for volcanic condi- tions, higher $\mathrm{H}_{2} \mathrm{SO}_{4}$ mixing ratios and temperatures of about $200 \mathrm{~K})$. Baran et al. (1993) have based a detection algorithm for sulfate aerosols from NOAA (National Oceanic and Atmospheric Administration) $-10,-11$ and $-12 \mathrm{ob}-$ servations on the simulated spectral absorption differences between about 800 and $1200 \mathrm{~cm}^{-1}$. Nevertheless, Grainger et al. (1993), Echle et al. (1998) and Baran et al. (1993) did not explicitly relate the observed absorption coefficient spectra to these specific molecular $\mathrm{H}_{2} \mathrm{SO}_{4}$ vibration modes. An increasing absorption has been observed in IASI observations of the volcanic plume emanated by Kasatochi eruption of 2008 and erroneously attributed to sulfate ionic absorption bands (Karagulian et al., 2010).

To further demonstrate the very small sensitivity of the sulfate extinction spectra to temperature, and the much more important contribution of the $\mathrm{H}_{2} \mathrm{SO}_{4}$ mixing ratio, we made a linear regression of the maximum extinction at $1170 \mathrm{~cm}^{-1}$ and its ratio to the minimum extinction near $800 \mathrm{~cm}^{-1}$, as a function of the temperature, at fixed mixing ratios (parameters of the regressions in Tables S1 and S2 in the Supplement), for background and volcanically enhanced situations. In general, the extinction does not vary much with temperature, except for a few cases, e.g. a $20 \%$ variation of the absolute extinction, from 183 to $293 \mathrm{~K}$, with a mixing ratio of $57 \%$ in both background and volcanic conditions. For other mixing ratios, the variation with temperature is less than $10 \%$. This variability is much more limited than that due to mixing ratio variations, which can be larger than $100 \%$ (for example, the maximum absorption at $1170 \mathrm{~cm}^{-1}$ varies from about $2.5 \times 10^{-3}$ to about $6.0 \times 10^{-3} \mathrm{~km}^{-1}$, and from about $2.5 \times 10^{-5}$ to about $6.0 \times 10^{-5} \mathrm{~km}^{-1}$, in volcanic and background conditions, respectively, with mixing ratios spanning 30 to $64 \%$ ). The variability of the relative extinction 1170 $800 \mathrm{~cm}^{-1}$ with temperature is even smaller.

These analyses of the dependence of the extinction coefficient on the temperature and $\mathrm{H}_{2} \mathrm{SO}_{4}$ mixing ratio point out that the temperature of the aerosol layer (and therefore its altitude) cannot be retrieved from aerosol extinction measurements, especially for mixing ratios greater than $60 \%$. From a different perspective, this is beneficial for the retrieval of sulfate aerosol chemical and microphysical parameters because this property limits the number of sensitive factors affecting the extinction spectra variability. The extinction, and more in particular the absorption signature, is very sensitive to the $\mathrm{H}_{2} \mathrm{SO}_{4}$ mixing ratio of the binary solution $\mathrm{H}_{2} \mathrm{SO}_{4} / \mathrm{H}_{2} \mathrm{O}$, both in background and volcanically enhanced situations, paving the way to a retrieval.

\subsection{Dependence of the extinction coefficient on the size distribution}

Figure 2 suggests that the sulfate extinction signature is sensitive to the size distribution of the aerosol layer. In this section, we systematically investigate this dependence by estimating the individual contributions of the number concentra- 

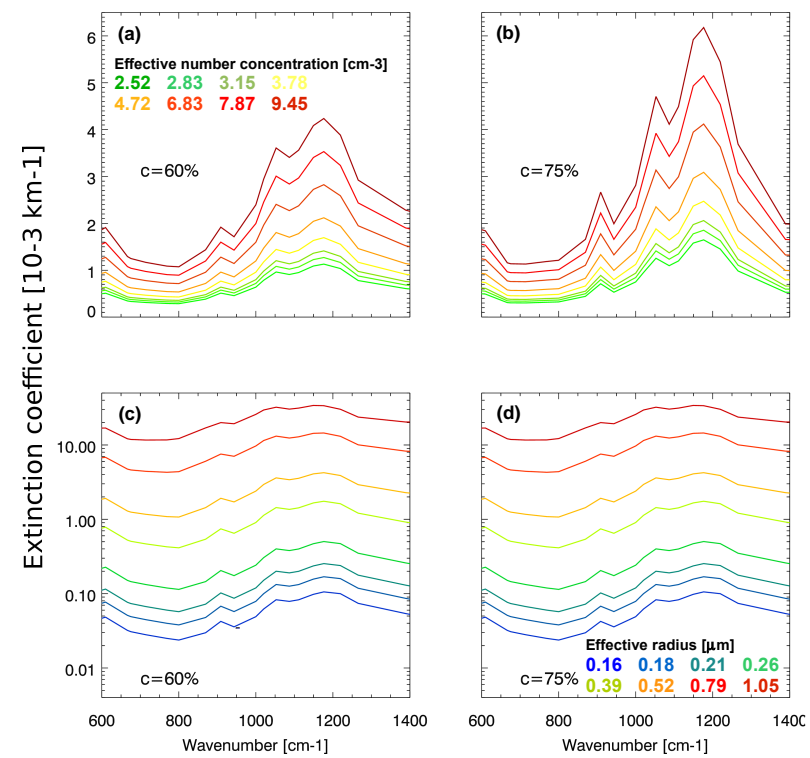

Figure 3. Spectral extinction coefficient for a sulfate aerosol layer, as a function of $(\mathbf{a}, \mathbf{b})$ the effective number concentration $N_{\mathrm{e}}$ (different number concentrations in different colours; see colourcoded legend) (c, d) the effective radius $r_{\mathrm{e}}$ (different radii in different colours, see colour-coded legend). Sulfate aerosol layers with 60 and $75 \%$ (values indicated in the plots) $\mathrm{H}_{2} \mathrm{SO}_{4}$ mixing ratios are considered at $213-215 \mathrm{~K}$. Please note the logarithmic ordinate in $(\mathbf{c}, \mathbf{d})$.

tion and effective radius. To conduct targeted analyses on the UTLS sulfate aerosols, we have limited the $\mathrm{H}_{2} \mathrm{SO}_{4}$ mixing ratio to four values, $60,64,70$ and $75 \%$, and the temperature to two close values, 213 and $215 \mathrm{~K}$, among those available in the database. This is intended to simulate typical tropical UTLS temperatures (see e.g. Lamsal et al., 2004) and typical mixing ratios within dehydrated atmospheric regions (SPARC, 2006). In this section, we let the size distribution parameters vary independently.

Figure $3 \mathrm{a}$ and $\mathrm{b}$ show the extinction coefficient in the spectral range $600-1400 \mathrm{~cm}^{-1}$ for these UTLS conditions, as a function of the effective number concentration $N_{\mathrm{e}}$, illustrating the proportionality shown in Eq. (10). The range of variation of $N_{\mathrm{e}}$ (see Table 2) covers background to severe volcanic conditions (i.e. Pinatubo-like). The effective radius $r_{\mathrm{e}}$ (corresponding $r_{\mathrm{m}}$ in parentheses) is fixed at 0.79 $(0.30) \mu \mathrm{m}$. The $\mathrm{H}_{2} \mathrm{SO}_{4}$ mixing ratio is fixed at $60 \%$ (a) and $75 \%$ (b). Figure $3 \mathrm{c}$ and d show the extinction coefficient in the spectral range $600-1400 \mathrm{~cm}^{-1}$ as a function of the effective radius $r_{\mathrm{e}}$. Note that in this figure the ordinate axis is logarithmic, to better show the spectral behaviour of the different curves. The effective number concentration $N_{\mathrm{e}}$ (corresponding $\mathrm{N}_{0}$ in parentheses) is now fixed at $7.87(20.00) \mathrm{cm}^{-3}$. The $\mathrm{H}_{2} \mathrm{SO}_{4}$ mixing ratio is fixed at $60 \%$ (c) and $75 \%$ (d). The spectral patterns of the sulfate/bisulfate ions and the sulfuric acid molecule are clearly visible for all effective num- ber concentrations and radii, with the same three marked peaks that emerged in Fig. 2. Figure $3 \mathrm{c}$ and $\mathrm{d}$ show that $F\left(c, r_{\mathrm{e}}, v\right)$ depends strongly on $r_{\mathrm{e}}$, growing monotonously with $r_{\mathrm{e}}$. The growth is not, however, uniform in $v$, as spectral extinction gets flatter with bigger sulfate particles. In general, the extinction is very small for smaller particles. Comparing Fig. 3a, b and 3a, c, it appears that the most important condition leading to significant extinction is a large effective radius of the layer. At a fixed $\mathrm{H}_{2} \mathrm{SO}_{4}$ mixing ratio, the variability of the extinction, e.g. at the maximum absorption at $1170 \mathrm{~cm}^{-1}$, due to the effective radius can be up to 2 orders of magnitude stronger than that due to the effective number concentration.

\subsection{Discussion on sulfate aerosol extinction}

\subsubsection{Broadband spectral features}

The spectral extinction of sulfate aerosol layers is, to different extents, sensitive to the three chemical and microphysical parameters under investigation, namely the $\mathrm{H}_{2} \mathrm{SO}_{4}$ mixing ratio, the effective radius and the effective number concentration.

In Sects. 3.2 and 3.3 we have analysed the dependence of the spectral extinction curves as a whole, in function of the chemical and microphysical properties: $\mathrm{H}_{2} \mathrm{SO}_{4}$ mixing ratio, the effective radius and the effective number concentration. We now fix the wavenumber. At a selected wavenumber $\bar{v}$ the extinction coefficient AE (absolute extinction) is (see Eq. 10)

$\mathrm{AE}=\beta_{\text {ext }}\left(c, r_{\mathrm{e}}, N_{\mathrm{e}}, \bar{v}\right)=N_{\mathrm{e}} \mathrm{F}\left(c, r_{\mathrm{e}}, \bar{v}\right)$.

We introduce the ratio RE (relative extinction) between the extinction coefficient at two different wavenumbers $v_{1}$ and $v_{2}$ :

$$
\begin{aligned}
\mathrm{RE} & =\frac{\beta_{\mathrm{ext}}\left(c, r_{\mathrm{e}}, N_{\mathrm{e}}, \nu_{1}\right)}{\beta_{\mathrm{ext}}\left(c, r_{\mathrm{e}}, N_{\left.\mathrm{e}, v_{2}\right)}\right.}=\frac{N_{\mathrm{e}} \mathrm{F}\left(c, r_{\mathrm{e}}, \nu_{1}\right)}{N_{\mathrm{e}} \mathrm{F}\left(c, r_{\mathrm{e}}, \nu_{2}\right)} \\
& =\mathrm{G}\left(c, r_{\mathrm{e}}, v_{1}, \nu_{2}\right) .
\end{aligned}
$$

The two functions $\mathrm{F}\left(c, r_{\mathrm{e}}, \bar{v}\right)$ and $\mathrm{G}\left(c, r_{\mathrm{e}}, \nu_{1}, \nu_{2}\right)$, as well as $\mathrm{AE}$ and $\mathrm{RE}$, depend on the choice of the wavenumbers $\bar{\nu}, \nu_{1}$ and $\nu_{2}$. The absolute and relative extinction at selected wavenumbers is important for remote sensing applications, in particular for radiometers that have broadband channels at a number of wavenumbers. Here we select specific wavenumbers where informative features of the spectral extinction of sulfate aerosol layers are found, as discussed in Sects. 3.2 and 3.3. Correspondingly, we introduce three spectral quantities: (1) the maximum $\mathrm{AE}$ at $1170 \mathrm{~cm}^{-1}$ (hereafter referred to as ME, maximum extinction), (2) its relative extinction with respect to the minimum extinction at $800 \mathrm{~cm}^{-1}$ (the extinction ratio between 1170 and $800 \mathrm{~cm}^{-1}$, hereafter referred to as RE1) and (3) the relative extinction of the secondary peak at $905 \mathrm{~cm}^{-1}$ with respect to the minimum extinction at $800 \mathrm{~cm}^{-1}$ (the extinction ratio between 905 and $800 \mathrm{~cm}^{-1}$, hereafter referred to as RE2). We recall 
that the extinction peaks at 1170 and $905 \mathrm{~cm}^{-1}$ are mostly due to molecular $\mathrm{H}_{2} \mathrm{SO}_{4}$ absorption bands. Another important spectral feature in the sulfate signature is the extinction peak due to the ionic absorption at $1050 \mathrm{~cm}^{-1}$, but we exclude the latter because the information in this band is disturbed by the ozone absorption band region at $9.6 \mu \mathrm{m}$ (more details in Sect. 5).

The variability of the spectral parameter $\mathrm{ME}$ as a function of the $\mathrm{H}_{2} \mathrm{SO}_{4}$ mixing ratio and effective radius and number concentration has been discussed in Sect. 3.3. As it can be seen from Fig. 3, ME varies between near-zero values (for small $N_{\mathrm{e}}, r_{\mathrm{e}}$ and $c$ ) and $40 \times 10^{-3} \mathrm{~km}^{-1}$ (large values of the three aerosol parameters). ME is very small for small effective radii, disregarding the value of the effective number concentration and $\mathrm{H}_{2} \mathrm{SO}_{4}$ mixing ratio. Higher values $\left(>10 \times 10^{-3}\right)$ are only found for effective radii bigger than about $0.5 \mu \mathrm{m}$. This is an indication of the small sensitivity of the spectral extinction to sulfate aerosols in background conditions, and the dominating role of the particle size in ME, as well as in the depth and the whole curve of the sulfate spectral extinction signature. Figure $4 a$ and $b$ show the variability of the spectral parameters RE1 and RE2 as a function of effective radius and $\mathrm{H}_{2} \mathrm{SO}_{4}$ mixing ratio, as $\mathrm{RE} 1$ and $\mathrm{RE} 2$ are independent of the effective number concentration (see Eq. 12). The behaviour of RE1 and RE2 is similar, with increasing values for higher $\mathrm{H}_{2} \mathrm{SO}_{4}$ mixing ratios and smaller particles.

As both RE1 and RE2 depend on $c$ and $r_{\mathrm{e}}$ but not on $N_{\mathrm{e}}$, it is useful to determine whether they differ in this dependency, having in mind the possibility of retrieving $c$ and $r_{\mathrm{e}}$ from spectrometric measurements. Figure $4 \mathrm{c}$ shows the angle $\alpha=\cos ^{-1}\left(\boldsymbol{\nabla} \boldsymbol{R} \boldsymbol{E} \mathbf{1}\left(c, r_{\mathrm{e}}\right) \cdot \boldsymbol{\nabla} \boldsymbol{R} \boldsymbol{E} 2\left(c, r_{\mathrm{e}}\right)\right)$ of the gradients of RE1 and RE2 with respect to $c$ and $r_{\mathrm{e}}$, normalised to vary over the same range. If the angle is near-zero, the gradients are parallel vectors and then the variations of RE1 and RE2 carry a very dependent information content. Conversely, for angles departing from zero, the information content about the aerosol parameters is more and more independent. It is visible that the angle remains small for small $r_{\mathrm{e}}$ and when both $r_{\mathrm{e}}$ and $c$ are large, and that there is an optimal sensitivity range which more or less extends about a diagonal from the upper left of the diagram, with angles between 15 and $30^{\circ}$.

To conclude this section, we suggest that these three broadband spectral parameters, ME, RE1 and RE2, could be used to detect and extract some quantitative information on UTLS sulfate aerosols, in the case of volcanically enhanced conditions. ME is sensitive to the three aerosol parameters, while RE1 and RE2 are only sensitive to the $\mathrm{H}_{2} \mathrm{SO}_{4}$ mixing ratio and the effective radius. In principle, the information content carried by ME, RE1 and RE2 on the $\mathrm{H}_{2} \mathrm{SO}_{4}$ mixing ratio, effective radius and number concentration is partially independent for most conditions and then broadband retrieval schemes could be developed using these three spectral parameters. One option could be to infer the $\mathrm{H}_{2} \mathrm{SO}_{4}$ mixing ratio and the effective radius from $\mathrm{RE} 1$ and $\mathrm{RE} 2$, and then use this information to derive the number concentration with ME1. In practice, due to the partial correlation of the information content of RE1 and RE2 to the $\mathrm{H}_{2} \mathrm{SO}_{4}$ mixing ratio and the effective radius, and the scarce sensitivity of ME to the effective number concentration for background nonvolcanic conditions, the sulfate aerosol parameters might be hardly retrievable in those conditions. However, in volcanically enhanced conditions, there is an enhanced variability of $\mathrm{ME}$ with respect to the three aerosol parameters but the variability of RE1 and RE2 with respect to the $\mathrm{H}_{2} \mathrm{SO}_{4}$ mixing ratio is relatively small, and the correlation of their information content is high for bigger values of the $\mathrm{H}_{2} \mathrm{SO}_{4}$ mixing ratio. All these considerations suggest that the three aerosol parameters are only retrievable as independent quantities for limited conditions when using broadband sulfate extinction spectral features, and that constraints should be given to at least one parameter (e.g. the effective number concentration). The approach of using absolute and relative extinction features is applicable to both high-resolution and broadband TIR satellite sensors as MODIS (Moderate Resolution Imaging Spectroradiometer) (Barnes et al., 1998) or SEVIRI (Spinning Enhanced Visible and InfraRed Imager), even if these latter instruments may not have optimised channels for sulfate aerosols observations. The information content of pseudo-observations based on broadband features (with different nadir instruments), and on high spectral resolution are discussed in Sect. 6. It can be noticed that the use of satellite observations at similar spectral intervals, i.e. broadband observations at about 800,900 and $1200 \mathrm{~cm}^{-1}$, has been proposed in the past to observe secondary sulfate aerosols after strong volcanic eruptions e.g. Ackerman and Strabala (1994).

\subsubsection{Size distribution sensitivity at fixed mass}

In the previous sections, the variability of the sulfate aerosol extinction coefficient has been studied as a function of the three parameters $N_{\mathrm{e}}, r_{\mathrm{e}}$ and $c$, by varying one parameter with the other two kept fixed. This has been done, having in mind the possibility of retrieving the three parameters from observations of the sulfate aerosol extinction. In any case, it must be considered that in real-world conditions, the variability of these parameters is constrained by the available sulfate mass. Then, it is instructive to study the variability of the spectral extinction coefficient as a function of these parameters, by keeping the mass fixed.

Figure 5 shows the extinction coefficient at $1170 \mathrm{~cm}^{-1}$ (the maximum extinction or ME; see Sect. 3.4.1) as a function of the effective radius $r_{\mathrm{e}}$ and effective number concentration $N_{\mathrm{e}}$, for fixed sulfate aerosol effective mass volume concentrations $M_{\mathrm{e}}$, as defined in Eq. (7). The ME variabilities are shown for two cases: background and volcanically enhanced conditions. Typical size distributions for these two cases, as defined in Sect. 3.1, are used to fix the background and volcanically enhanced mass. The value of $c$ has been kept fixed at 60 (background) and $75 \%$ (volcanically enhanced con- 

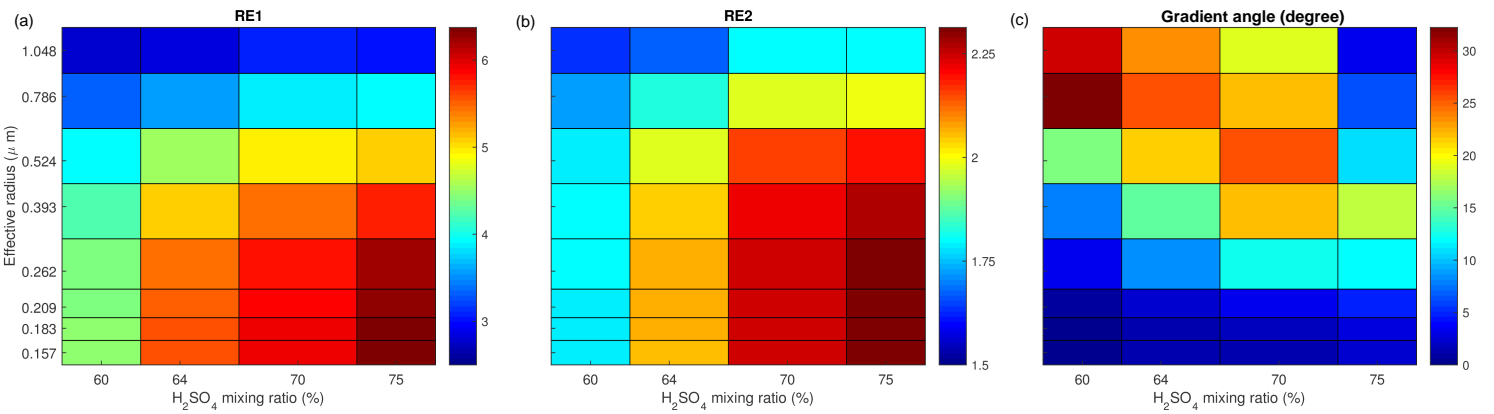

Figure 4. RE1 (a) and RE2 (b) as a function of the effective radius and $\mathrm{H}_{2} \mathrm{SO}_{4}$ mixing ratio. Please note the different scaling of the colour bars. Arc cosine of the scalar product $\nabla \boldsymbol{R E 1} \cdot \nabla \boldsymbol{R E 2}(\mathbf{c})$. The gradients are normalised.
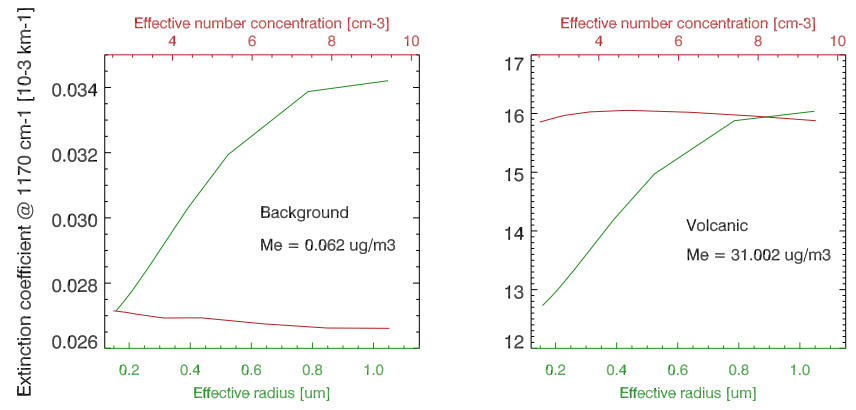

Figure 5. Extinction coefficient at $1170 \mathrm{~cm}^{-1}$ (maximum extinction, ME) as function of the effective radius $r_{\mathrm{e}}$ (green line) and effective number concentration $N_{\mathrm{e}}$ (red line), for fixed sulfate aerosol effective mass volume concentrations $M_{\mathrm{e}}\left(0.062 \mu \mathrm{g} \mathrm{m}^{-3}\right.$ : background conditions - left panel; $31.002 \mu \mathrm{g} \mathrm{m}^{-3}$ : volcanically enhanced conditions - right panel).

ditions). The fixed $M_{\mathrm{e}}$ values are then $0.062 \mu \mathrm{g} \mathrm{m}{ }^{-3}$ (background) and $31.002 \mu \mathrm{g} \mathrm{m}^{-3}$ (volcanically enhanced conditions).

The sulfate extinction is 2 orders of magnitude stronger for a volcanically typical mass with respect to background. By keeping $M_{\mathrm{e}}$ fixed, the sulfate extinction varies by more than $20 \%$ from smaller to bigger $r_{\mathrm{e}}$, in both conditions. The dependence on $N_{\mathrm{e}}$, on the contrary, is very limited. These further simulations allow most of the variability to be attributed to the size distribution parameters, as described in Sect. 3.3, to the increment of sulfate mass when increasing $N_{\mathrm{e}}$ or/and $r_{\mathrm{e}}$. In particular, the dominant role of $r_{\mathrm{e}}$ in determining significant extinction signatures is mostly due to an increase of the sulfate mass in the presence of bigger particles. Nevertheless, even at fixed $M_{\mathrm{e}}$, there is a significant additional variability of the extinction with varying $r_{\mathrm{e}}$. This evidence confirms that $r_{\mathrm{e}}$ is the dominant factor determining the sensitivity of the sulfate aerosol extinction spectra.

\section{Spectral sensitivity of IASI pseudo-observations to chemical and microphysical properties}

In order to test the sensitivity of satellite nadir observations in the TIR to sulfate aerosols and the perturbation brought by other atmospheric species under real conditions, the spectral extinction coefficients of the sulfate aerosol layers obtained in Sect. 3 are used here as inputs of the forward radiative transfer modelling described in Sect. 2. As done for Sects. 3.3 and 3.4.1, we restrict our attention to $\mathrm{H}_{2} \mathrm{SO}_{4}$ mixing ratios of $60,64,70$ and $75 \%$ and temperature of the droplets of $213-215 \mathrm{~K}$, within the set of tabulated values. As demonstrated in Sect. 3.2, the extinction properties of the $\mathrm{H}_{2} \mathrm{SO}_{4} / \mathrm{H}_{2} \mathrm{O}$ droplets layers are very weakly dependent on the temperature. The chosen parameters are intended to mimic a realistic tropical UTLS situation, given the constraints of our data set. The altitude of the sulfate aerosol layer has been fixed at about $150 \mathrm{hPa}$. A typical tropical atmosphere (temperature, humidity and gas concentration profiles) is selected from those available in $4 \mathrm{~A} / \mathrm{OP}$. Then we conduct 256 simulations by varying the four $\mathrm{H}_{2} \mathrm{SO}_{4}$ mixing ratio/temperature combinations and all the available effective number concentrations and effective radii (see Tables 2 and 1). A further simulation is made with the same atmosphere but without a sulfate aerosol layer, to define a baseline and to isolate the sulfate aerosol impact on the output spectra. Finally, 256+1 IASI spectral BT pseudo-observations are obtained. We then define a sulfate aerosol brightness temperature signature (hereafter simply referred to as BT signature) as the spectral differences between each of the 256 brightness temperature spectra and the one obtained with the baseline run. Figure 6 shows examples of BT signatures for different combinations of the effective number concentration, the effective radius and the $\mathrm{H}_{2} \mathrm{SO}_{4}$ mixing ratio. In the spectral region $700-1300 \mathrm{~cm}^{-1}$ a few main interfering features emerge, like the ubiquitous weak absorption bands of $\mathrm{H}_{2} \mathrm{O}$ and the strong rotational-vibrational ozone band centred at $9.6 \mu \mathrm{m}\left(1041.67 \mathrm{~cm}^{-1}\right)$ and affecting the spectral region of approximately $980-1080 \mathrm{~cm}^{-1}$ (see also Fig. 9). An initial finding is that the signal of the bisulfate ion bands at 1030 and 
$1050 \mu \mathrm{m}$ is affected by the interference with the ozone band. This justifies discarding these absorption features in the discussion of Sect. 3.4.1. The sulfate ion band at $1104 \mathrm{~cm}^{-1}$ and the weaker bisulfate band at $965 \mathrm{~cm}^{-1}$ are partially also affected by the peripheral region of the ozone band. Therefore, it is very hard to use the ionic bands to infer useful information on sulfate aerosols. This is mostly inconvenient for small mixing ratios, where ionic absorption dominates over molecular absorption (see Fig. 2). On the contrary, the molecular $\mathrm{H}_{2} \mathrm{SO}_{4}$ absorption band at $1170 \mathrm{~cm}^{-1}$, as well as the weaker $\mathrm{H}_{2} \mathrm{SO}_{4}$ band at $905 \mathrm{~cm}^{-1}$ and the background region at $800 \mathrm{~cm}^{-1}$ are clearly visible, while still partly affected by the weak, fine-scale, ubiquitous water absorption lines.

The stronger band at $1170 \mathrm{~cm}^{-1}$ is the most important feature in the sulfate aerosol extinction spectra and is responsible of the typical increasing extinction or decreasing BT signature shape between 700 and $1200 \mathrm{~cm}^{-1}$, which has been empirically observed in the past (see e.g. Grainger et al., 1993; Echle et al., 1998; Clarisse et al., 2010; Griessbach et al., 2015). In Sect. 3 it was found that the extinction signature of the sulfate aerosols, and the three partially independent spectral parameters, ME, RE1 and RE2, are sensitive to the $\mathrm{H}_{2} \mathrm{SO}_{4}$ mixing ratio and to the size distribution, and this sensitivity is dominated by the effective radius. Consistently, from Fig. 6 it can be seen that the depth of the BT signature (and then ME) is strongly dependent on the effective radius and much less sensitive to the effective number concentration and the $\mathrm{H}_{2} \mathrm{SO}_{4}$ mixing ratio. However, for fixed effective radius and number concentration, there is a variation of the spectral slope between 700 and $1200 \mathrm{~cm}^{-1}$ with the $\mathrm{H}_{2} \mathrm{SO}_{4}$ mixing ratio. This is again consistent with the results of Sect. 3.4.1. In general, the BT signatures at $1170 \mathrm{~cm}^{-1}$ are less than $0.7 \mathrm{~K}$ for small particles, with effective radii smaller than $0.52 \mu \mathrm{m}$ for all number concentrations and $\mathrm{H}_{2} \mathrm{SO}_{4}$ mixing ratios. The $\mathrm{BT}$ signatures at $1170 \mathrm{~cm}^{-1}$ can reach values of 3.0 to $5.0 \mathrm{~K}$ for bigger particles, with higher values for larger number concentration and $\mathrm{H}_{2} \mathrm{SO}_{4}$ mixing ratio. Values of $r_{\mathrm{e}}$ of $0.6-0.7 \mu \mathrm{m}$ and higher are typical of coagulation effects in more or less severe volcanically enhanced conditions. Thus, it seems very arduous to observe the background sulfate aerosol layers, while BT signatures of volcanic sulfates can be relatively strong.

The variability of the spectral BT signature with effective number concentration, effective radius and $\mathrm{H}_{2} \mathrm{SO}_{4}$ mixing ratio is more systematically displayed in Fig. 7. This figure shows the BT signature in the spectral range $700-1300 \mathrm{~cm}^{-1}$, as a function of the effective number concentration $N_{\mathrm{e}}$, for a fixed effective radius $r_{\mathrm{e}}=0.79 \mu \mathrm{m}$, and as a function of the effective radius $r_{\mathrm{e}}$, for a fixed effective number concentration $N_{\mathrm{e}}=7.87$ particles $\mathrm{cm}^{-3}$. The same patterns evidenced in Fig. 6, the discussion above and the results of Sect. 3 are systematically observed in these plots. A marked maximum of the BT signature at $1170 \mathrm{~cm}^{-1}$, as well as a secondary maximum at $905 \mathrm{~cm}^{-1}$, both due to the molecular $\mathrm{H}_{2} \mathrm{SO}_{4}$ absorption, are apparent. The dramatic difference for Fig. 7c
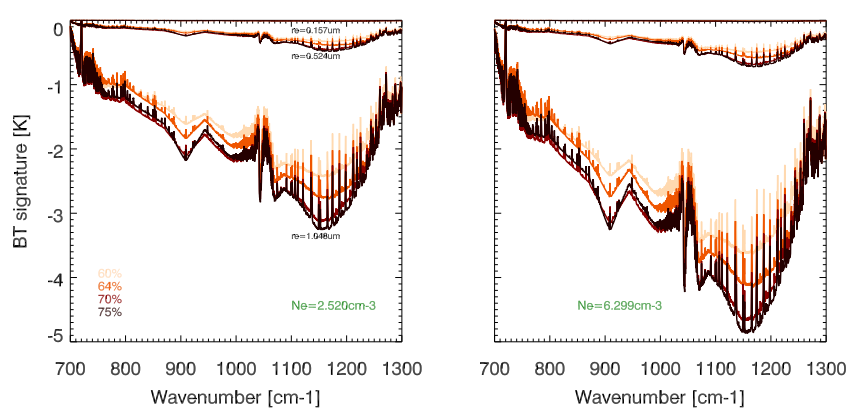

Figure 6. BT signature of sulfate aerosol layers, for effective number concentrations of 2.52 (left panel) and 6.30 particles $\mathrm{cm}^{-3}$ (right panel), for effective radii of $0.16,0.52$ and $1.05 \mu \mathrm{m}$ (see text in the figures) and $\mathrm{H}_{2} \mathrm{SO}_{4}$ mixing ratios of $60,64,70$ and $75 \%$ (in different colours).
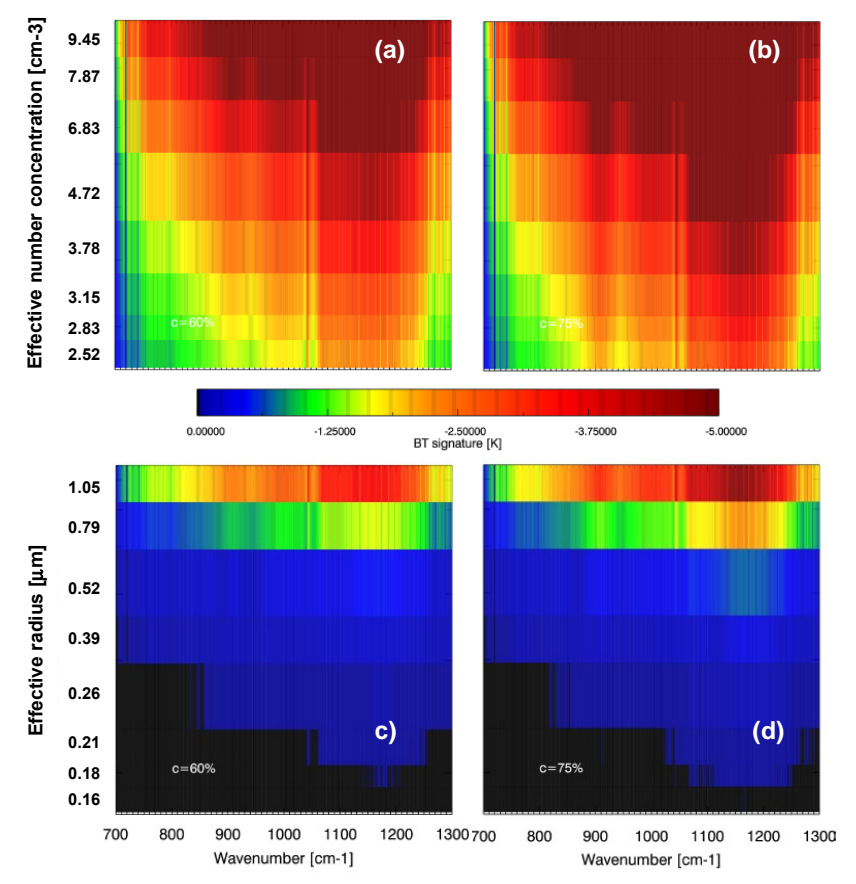

Figure 7. Spectral BT signatures for a sulfate aerosol layer at about $150 \mathrm{hPa}$ altitude, as a function of the effective number concentration $N_{\mathrm{e}}$ for a fixed effective radius $r_{\mathrm{e}}=0.79 \mu \mathrm{m}(\mathbf{a}, \mathbf{b})$, and as a function of the effective radius $r_{\mathrm{e}}$ for a fixed effective number concentration $N_{\mathrm{e}}=7.87$ particles $\mathrm{cm}^{-3}$ (c, d). Sulfate aerosol layers are considered with $60 \%(\mathbf{a}, \mathbf{c})$ and $75 \%(\mathbf{b}, \mathbf{d}) \mathrm{H}_{2} \mathrm{SO}_{4}$ mixing ratios at 213-215 K.

and $\mathrm{d}$ from smaller to bigger effective radii, is a confirmation of the relative importance of the effective radius in determining the signature of the UTLS sulfate aerosols in TIR spectra, and the very low sensitivity at background conditions.

The analyses of the present section, in conjunction with the discussion of Sect. 3.4.1, suggest that information on chemical and microphysical properties of sulfate aerosols can be extracted using broadband spectral features, e.g. the maxi- 

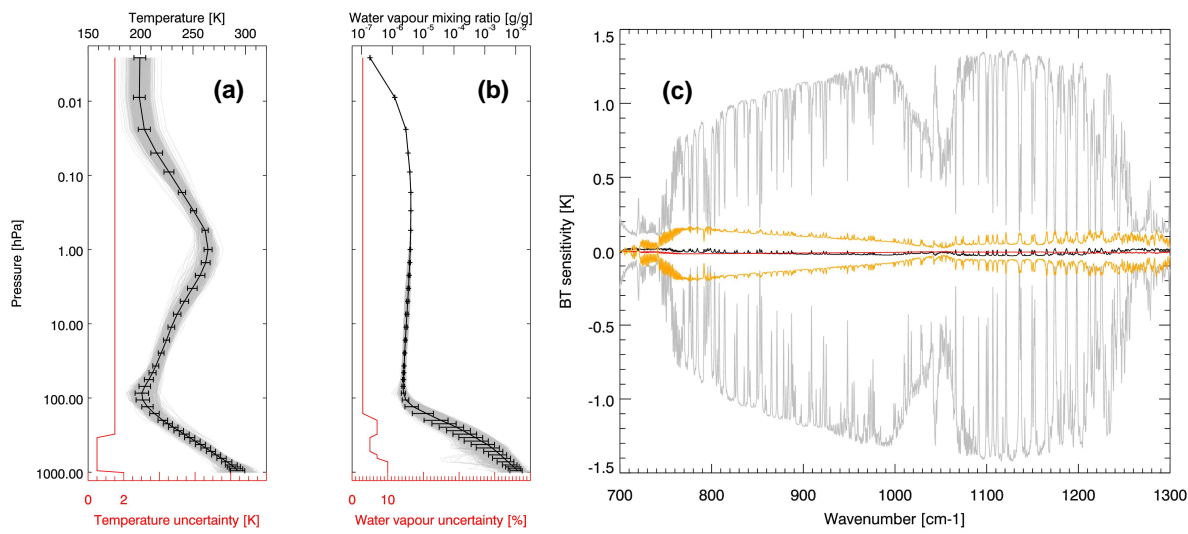

Figure 8. Individual (grey) and average TIGR tropical vertical profiles with standard deviations (black), for temperature (a) and water vapour mixing ratio (b). The standard deviation of the Gaussian noise used to generate the perturbed profiles is in red in both figures; spectral BT sensitivity for temperature profile (mean differences in black, 1 standard deviation interval in grey) and water vapour profile variability (mean differences in red, 1 standard deviation interval in orange) (c). See text for further details on how this sensitivity is evaluated.

mum absorption near $1170 \mathrm{~cm}^{-1}$, and the spectral ratios between 1170 and $800 \mathrm{~cm}^{-1}$ and between 905 and $800 \mathrm{~cm}^{-1}$. Nevertheless, the presence of relatively well-separated ionic and molecular absorption signatures justify the use of a spectral fitting approach to extract the full information content using finer spectral resolution. These fine-scale structures are typical of liquid aerosols. Thus, we wish to stress how highspectral-resolution observations, like those made by IASI, can bring a significant added value to the characterisation of such aerosols.

\section{Interfering parameters}

\subsection{Interference with temperature and humidity profiles variability}

We consider here how uncertainties in the temperature and humidity profile may mask the sensitivity to sulfate aerosols. The TIGR (Thermodynamic Initial Guess Retrieval) database is a library of 2311 representative atmospheric situations (tropical, mid-latitude and polar) selected by statistical methods from an ensemble of 80000 radiosonde measurements (Chédin et al., 1985; Chevallier et al., 1998). We have calculated the average temperature and water vapour mixing ratio profile from TIGR. Only the tropical atmosphere situations ( 872 profiles) have been considered. Figure $8 \mathrm{a}$ and $\mathrm{b}$ show the individual tropical temperature and water vapour profiles, respectively, and the average profiles with standard deviations. We then generate two data sets of 128 profiles each, by perturbing the average temperature (one set of 128 perturbed profiles) and water vapour profile (one set of 128 perturbed profiles) with a height-dependent Gaussian noise. For each level, we added a random value from a Gaussian distribution of zero mean value and variable standard deviation, depending on the al- titude level, to simulate the actual temperature and water vapour retrieval uncertainties of IASI, as estimated e.g. by Pougatchev et al. (2009). In this latter work, temperature and water vapour profile uncertainties are estimated by comparing a data set of IASI temperature and water vapour profile retrievals with co-located radiosonde profiles. The standard deviations of the Gaussian perturbation are assumed between 0.5 and $2.0 \mathrm{~K}$ (temperature) and between 3 and $10 \%$ (water vapour mixing ratio), as shown in Fig. 8a and b, respectively. We then performed two sets of $1284 \mathrm{~A} / \mathrm{OP}$ forward radiative transfer runs with (1) the average temperature profile and the 128 perturbed water vapour profiles $\left(\mathrm{H}_{2} \mathrm{O}\right.$-perturbed runs), (2) the average water vapour profile and the 128 perturbed temperature profile (T-perturbed runs), and a further run with average temperature and water vapour profiles (baseline run for this analysis). For these runs, the sulfate aerosol layer size distribution and chemical composition have been taken fixed at moderate volcanic conditions (log-normal distribution with $N_{0}=20 \mathrm{~cm}^{-3}, r_{\mathrm{m}}=0.2 \mu \mathrm{m}, \sigma_{\mathrm{m}}=1.86 \mu \mathrm{m}, 70 \%$ $\mathrm{H}_{2} \mathrm{SO}_{4}$ mixing ratio) at about $150 \mathrm{hPa}$ altitude. Two sets of spectral differences are finally calculated: a first set of differences between the T-perturbed and the baseline runs, and a second set of differences between the $\mathrm{H}_{2} \mathrm{O}$-perturbed and the baseline runs. Figure $8 \mathrm{c}$ shows the mean values of $\mathrm{T}$ perturbed minus baseline, and $\mathrm{H}_{2} \mathrm{O}$-perturbed minus baseline differences and spectral variability (represented by its 1 standard deviation interval) of these differences.

The temperature profile uncertainties dominate the spectral brightness temperature variability, with a sensitivity up to $\pm 1.4 \mathrm{~K}$, peaking in the sulfate-sensitive spectral region between 1100 and $1200 \mathrm{~cm}^{-1}$, while the impact of water vapour concentration profile uncertainties is generally smaller than $\pm 0.2 \mathrm{~K}$. The broadband magnitude of these fluctuations indicates a further limitation of the observations of sulfate aerosol chemical and microphysical properties in 
non-volcanically perturbed conditions with IASI-like instruments, at least for BT sulfate signatures smaller than about $2.0 \mathrm{~K}$ (see Fig. 6). At a finer spectral resolution, it is clear that the regions characterised by water vapour absorption lines must be avoided by a careful selection of the spectral microwindows of the retrieval algorithm.

The previous analysis was aimed at the evaluation of the impact of the temperature and humidity profile uncertainties when these quantities are retrieved with the same TIR observations used to infer the sulfate aerosol properties. This discussion is then of interest when considering near-real time multi-parameter retrievals. In offline retrieval schemes, temperature and humidity profiles can be taken from model reanalyses. It must be noted that these profiles have significantly smaller uncertainties than profiles obtained with TIR observations, then in these cases their impact on the retrieval of sulfate aerosols is more limited.

\subsection{Other interfering species: $\mathrm{SO}_{2}, \mathrm{CO}_{2}$ and ash}

In the TIR spectral region where sulfate aerosols have their absorption features ( $700-1300 \mathrm{~cm}^{-1}$ ), other gaseous species have absorption bands, which can interfere with the sulfate BT signature. Figure 9 shows the absorption cross sections of water vapour, carbon dioxide, ozone and sulfur dioxide in this spectral range. As discussed in Sects. 4 and 5.1, the water vapour lines are ubiquitous and must be taken into account when selecting the spectral micro-windows of a retrieval algorithm; at the same time, the ozone band perturbs the region between about 980 and $1080 \mathrm{~cm}^{-1}$, thus preventing from using the sulfate ions bands around $1050 \mathrm{~cm}^{-1}$. The sulfur dioxide absorption bands lie in the range $1080-1230 \mathrm{~cm}^{-1}$ and then can partially affect the maximum sulfate absorption region around $1170 \mathrm{~cm}^{-1}$. The use of high-resolution TIR spectrometers, like IASI, is then recommendable to select targeted spectral micro-windows to minimise the effect of the sulfur dioxide interference, e.g. around $1150 \mathrm{~cm}^{-1}$. The carbon dioxide bands are stronger for wavenumbers less then about $750 \mathrm{~cm}^{-1}$, and then of lower concern for the present study. It is interesting to note that enhanced concentrations of sulfur dioxide, carbon dioxide and water vapour are coexistent with sulfate aerosols in volcanic plumes, where the sulfate BT signature is stronger.

Another important volcanic effluent that has a spectral signature in the range $700-1300 \mathrm{~cm}^{-1}$ is the ash. The ash BT signature has a typical $\mathrm{V}$ shape in this range, as shown e.g. by Clarisse et al. (2010), Karagulian et al. (2010) and Dubuisson et al. (2014), which can be modulated by its mineralogical composition (Dubuisson et al., 2014) and optical depth (Corradini et al., 2009). This ash BT signature is characterised by a stronger absorption at about $950-1100 \mathrm{~cm}^{-1}$ than at longer $\left(1200 \mathrm{~cm}^{-1}\right)$ and shorter wavenumbers $\left(850 \mathrm{~cm}^{-1}\right)$, as shown in Fig. 1b of Clarisse et al. (2010). In Fig. 10 the impact of different UTLS sulfate aerosol layers on the top of the atmosphere (TOA) radiance spectra, as for our simulations, is

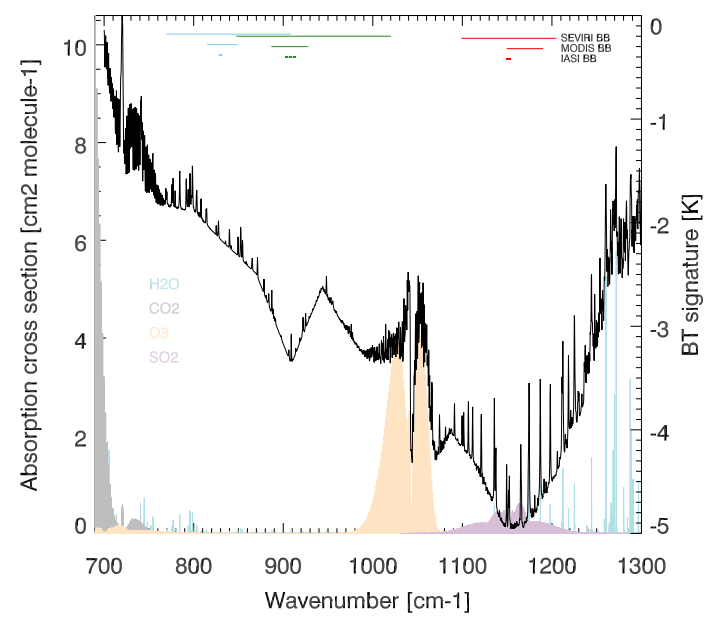

Figure 9. Absorption cross sections of water vapour (multiplied by a factor of 30 to enhance visualisation; light blue), carbon dioxide (grey), ozone (orange) and sulfur dioxide (violet) in the spectral range $700-1300 \mathrm{~cm}^{-1}$. A typical sulfate aerosol BT signature is overplotted (black). The spectral ranges of the channels used for IASI BB, MODIS BB and SEVIRI BB instrumental configurations (broadband features) are also reported (sky blue, green and red lines and points).

shown. The spectra are expressed in radiance units as a function of the wavelength to more readily compare the impact of the sulfate absorption with the impact of ash, as reported in Fig. 1 of Corradini et al. (2009). The reduction of the TOA radiance due to ash is typically 10 to $25 \%$ at its maximum absorption spectral range (about $10-11 \mu \mathrm{m}, 1000-910 \mathrm{~cm}^{-1}$ ), depending on the ash optical depth. Sulfates can impact for a few percent, for small and diluted droplets (green lines in Fig. 10), to up to about $25 \%$ for volcanically enhanced conditions (red lines in Fig. 10) at its maximum extinction spectral range (about $8.5-9.0 \mu \mathrm{m}, 1175-1110 \mathrm{~cm}^{-1}$ ). As pointed out by Clarisse et al. (2010), the different shapes of the ash and sulfate absorption signatures facilitate the discrimination of the two different aerosol particles. In addition, in extreme volcanic conditions, the magnitude of the sulfate signature is comparable to that of ash. The comparison of Figs. 10 and 1 of Corradini et al. (2009) permits as well the comparison of the impact of sulfate aerosols and that of sulfur dioxide absorptions on the TOA radiances. The latter is generally a few percent, with a maximum at about $9 \mu \mathrm{m}\left(1110 \mathrm{~cm}^{-1}\right)$, and so it is comparable to the sulfate aerosol impact for background to moderate volcanic conditions.

\section{Information content analysis: high spectral resolution and broadband spectral features approaches}

The information on the three sulfate aerosol parameters $\left[N_{\mathrm{e}}\right.$, $\left.r_{\mathrm{e}}, c\right]$ contained in the pseudo-observations with different in- 


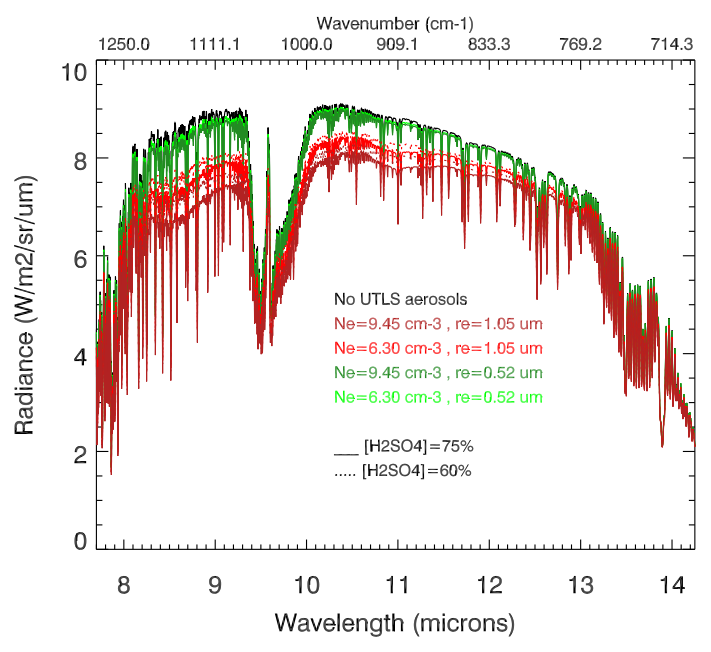

Figure 10. Simulated radiances for baseline no UTLS aerosol conditions (black) and different UTLS aerosols with different $\mathrm{H}_{2} \mathrm{SO}_{4}$ mixing ratios, effective radii and effective number concentrations (light and dark green and red; please see legend for details). The abscissa is expressed in both wavelength (to more readily compare with Fig. 1 of Corradini et al., 2009) and wavenumber.

strumental configurations is investigated in the present section. In particular, we define one high-spectral-resolution configuration (IASI HR; the full IASI BT spectra pseudoobservations are described in Sect. 4) and three configurations based on the broadband spectral features introduced in Sect. 3.4.1. We have derived related quantities of the three broadband features (ME, RE1 and RE2) to simulate IASI, MODIS and SEVIRI observations. For IASI (IASI BB) we have produced three inputs by averaging the BT pseudoobservations in the following bands: (1) $829-831 \mathrm{~cm}^{-1}$ (minimum sulfates extinction), (2) 903 and $913 \mathrm{~cm}^{-1}$ (secondary extinction peak around $905 \mathrm{~cm}^{-1}$ ) and (3) 1150 and $1154 \mathrm{~cm}^{-1}$ (maximum sulfates extinction). We have empirically tried to avoid water vapour absorption lines in these bands by a careful wavenumber selection. For MODIS (MODIS BB) we have convolved the high-resolution IASI BT pseudo-observations using the relative spectral response functions of channels 32 (central wavelength $12.02 \mu \mathrm{m}$, central wavenumber $831.9 \mathrm{~cm}^{-1}$ ), 31 (central wavelength $11.03 \mu \mathrm{m}$, central wavenumber $906.6 \mathrm{~cm}^{-1}$ ) and 29 (central wavelength $8.55 \mu \mathrm{m}$, central wavenumber $1169.6 \mathrm{~cm}^{-1}$ ). For SEVIRI (SEVIRI BB) we have convolved the highresolution IASI BT pseudo-observations using the relative spectral response functions of channels 10 (central wavelength $12.0 \mu \mathrm{m}$, central wavenumber $833.3 \mathrm{~cm}^{-1}$ ), 9 (central wavelength $10.8 \mu \mathrm{m}$, central wavenumber $925.5 \mathrm{~cm}^{-1}$ ) and 7 (central wavelength $8.7 \mu \mathrm{m}$, central wavenumber $1149.4 \mathrm{~cm}^{-1}$ ). The relative spectral response functions for MODIS and SEVIRI are available on the following websites, respectively: http://modis.gsfc.nasa.gov/ about/specifications.php and http://oiswww.eumetsat.org/
WEBOPS/msg_interpretation/msg_channels.php. The selected wavenumbers of IASI BB and the spectral channels used for MODIS BB and SEVIRI BB configurations are shown in Fig. 9.

The full characterisation of the information content of the observations is provided by the matrices AK (averaging kernel matrix) and $\mathbf{S}_{x}$ (total error covariance matrix).

AK represents the sensitivity of the retrieved state $\hat{\boldsymbol{x}}$ to the true state $\boldsymbol{x}$, and can be calculated as follows (Rodgers, 2000):

$\mathbf{A K}=\partial \hat{\boldsymbol{x}} / \partial \boldsymbol{x}=\left(\mathbf{K}^{\mathrm{T}} \mathbf{S}_{\epsilon}^{-1} \mathbf{K}+\mathbf{S}_{\mathrm{a}}^{-1}\right)^{-1} \mathbf{K}^{\mathrm{T}} \mathbf{S}_{\epsilon}^{-1}$.

In Eq. (13), $\mathbf{K}=\partial \mathrm{F}(\mathrm{x}) / \partial \mathbf{x}$ is the Jacobian matrix, and $\mathbf{S}_{\epsilon}$ and $\mathbf{S}_{\mathrm{a}}$ are the measurement error covariance and the a priori covariance matrices. The trace of the $\mathbf{A K}$ matrix represents the degrees of freedom (DOF) of the measurement (Rodgers, 2000). In our case this value varies between 0 and 3 , with this latter value meaning that the three aerosol parameters $\left[N_{\mathrm{e}}, r_{\mathrm{e}}\right.$, $c$ ] can be retrieved as perfectly independent quantities.

$\mathbf{S}_{\mathbf{x}}$ represents the total uncertainty on the retrieved aerosol parameters. If the forward model error and the error associated to non-retrieved parameters (see discussion for temperature and humidity profiles in Sect. 5.1) is excluded, the total error covariance matrix can be written as

$$
\begin{aligned}
\mathbf{S}_{\mathbf{x}}= & \mathbf{S}_{\mathbf{s m}}+\mathbf{S}_{\mathbf{m}}=(\mathbf{A} \mathbf{K}-\mathbf{I}) \mathbf{S}_{\mathbf{a}}(\mathbf{A K}-\mathbf{I})^{\mathbf{T}}+\left(\mathbf{K}^{\mathbf{T}} \mathbf{S}_{\epsilon}^{-1} \mathbf{K}+\mathbf{S}_{\mathbf{a}}^{-1}\right) \\
& \mathbf{S}_{\epsilon}\left(\mathbf{K}^{\mathbf{T}} \mathbf{S}_{\epsilon}^{-1} \mathbf{K}+\mathbf{S}_{\mathbf{a}}^{-1}\right)^{\mathbf{T}} .
\end{aligned}
$$

In Eq. (14), $\mathbf{S}_{\mathrm{sm}}$ and $\mathbf{S}_{\mathbf{m}}$ represent the contribution due to the correlation of the retrieved parameters (smoothing error component) and to the spectral measurement noise (measurement error component). The square roots of the diagonal elements of $\mathbf{S}_{\mathbf{x}}$ represent the total error of the retrieved aerosol parameters.

The measurement error covariance matrices $\mathbf{S}_{\epsilon}$ for the four instrumental configurations are assumed diagonal, with the $i$ th diagonal element derived from the standard deviation of the BT measurements in the following way: $\mathbf{S}_{\epsilon, i}=\sigma_{\epsilon, i}^{2}$. The values of $\sigma_{\epsilon, i}$ are assumed as the noise equivalent brightness temperature (NEBT) for each instrumental configuration. For IASI HR, the NEBT has been assumed $0.2 \mathrm{~K}$ at all wavenumber. For IASI BB, the standard deviation for each of the three broadband features is calculated as $\sigma_{\epsilon, i}=0.2 \mathrm{~K} / \sqrt{\left(n_{i}\right)}$, where $n_{i}$ is the number of individual wavenumbers averaged to obtain the $i$ th broadband feature. For MODIS BB, a NEBT of $0.05 \mathrm{~K}$ is assumed for channels 32, 31 and 29 (Wan, 2002). For SEVIRI BB, NEBTs of $0.93,0.94$ and $0.80 \mathrm{~K}$ are assumed for channels 10, 9 and 7 (www.eumetsat.int/website/wcm/idc/ idcplg?IdcService=GET_FILE $\&$ dDocName=PDF_TYP RADIOMET_ACC_MSG-1-2\&RevisionSelectionMethod= LatestReleased\&Rendition=Web).

The a priori covariance matrix is the same for the four instrumental configurations. It is assumed diagonal, with the 
Table 3. Degrees of freedom (DOF) for the retrieval of the three aerosol parameters: $N_{\mathrm{e}}, r_{\mathrm{e}}$ and $\mathrm{H}_{2} \mathrm{SO}_{4}$ mixing ratio, with different instrumental configurations (IASI HR refers to the IASI high spectral resolution; IASI BB refers to IASI broadband features; MODIS $\mathrm{BB}$ refers to MODIS broadband features; SEVIRI BB refers to SEVIRI broadband features. See the text for further details). DOF are calculated for typical background (Bg) and volcanic (Volc) conditions.

\begin{tabular}{lrrrr}
\hline & IASI HR & IASI BB & MODIS BB & SEVIRI BB \\
\hline Bg & 1.34 & 0.24 & 0.22 & 0.01 \\
Volc & 2.70 & 2.41 & 2.11 & 1.48 \\
\hline
\end{tabular}

$i$ th diagonal element taken as $100 \%$ of the three aerosol parameters values. This means that the a priori knowledge of the parameters $\left[N_{\mathrm{e}}, r_{\mathrm{e}}, c\right]$ is supposed to be within $100 \%$ of the true value.

The DOF and the total error, calculated for the four instrumental configurations and for a typical background and volcanically enhanced conditions (as defined in Sect. 3.1), are listed in Tables 3 and 4. One important result is that high spectral resolution is particularly critical in background conditions. In these conditions, broadband features provide strongly dependent information on $\left[N_{\mathrm{e}}, r_{\mathrm{e}}, c\right]$, with all instruments (DOF for IASI, MODIS and SEVIRI BB are 0.24 , 0.22 and 0.01 , and total error higher than $100 \%$, except for $c$ retrievals with IASI BB). The DOF for IASI HR for aerosols at background conditions is 1.34 , so more than one independent piece of information is retrievable. Nevertheless, even with IASI HR, background $N_{\mathrm{e}}$ has a total error higher than $100 \%$, while retrieval uncertainties on $r_{\mathrm{e}}$ and $c$ are around $35 \%$. For volcanically enhanced conditions, the added value of the high spectral resolution, with respect to broadband features, is smaller than at background conditions. Broadband features are reasonably well adapted to characterise chemical and microphysical properties of sulfate aerosols in volcanic conditions. In the best case (IASI HR, volcanic conditions) we have found a DOF of 2.7 and retrieval uncertainties of about 30,15 and $10 \%$ for $N_{\mathrm{e}}, r_{\mathrm{e}}$ and $c$. This indicates three quasi-independent pieces of information with relatively small retrieval uncertainties.

Our error estimations for $r_{\mathrm{e}}$ and $c$ can be compared with those made by Steele et al. (2006). In that work, the retrieval uncertainty is evaluated using ACE-FTS pseudoobservations, covering the spectral range from 800 to $4750 \mathrm{~cm}^{-1}$. Different spectral configurations (different subbands of the overall spectral region of their pseudoobservations) are discussed, including a configuration similar to out IASI HR (an interval of about $800-1200 \mathrm{~cm}^{-1}$, called f1 in Steele et al., 2006). For that configuration, the total error for $r_{\mathrm{e}}$ and $c$ is between $>100$ and $40 \%$ (depending on the value of $r_{\mathrm{e}}$ ), and about 25 and $20 \%$ (depending on the value of $c$ ), at conditions roughly similar to what we call background conditions. Our estimated uncertainties
(37.1 and $35.9 \%$, for $r_{\mathrm{e}}$ and $c$ ), even if comparable, are somewhat lower for $r_{\mathrm{e}}$ and higher for $c$. For extreme $r_{\mathrm{e}}$ and $c$ values, Steele et al. (2006) found corresponding uncertainties reaching values as low as 10 and $15 \%$ (our estimations for volcanically enhanced conditions are 17.6 and $10.8 \%$ ). One reason for these relatively small discrepancies might be the different instrumental characterisation of ACE-FTS and IASI, including the different observation geometry. In any case, our results are quite consistent with those obtained by Steele et al. (2006) It is worth noticing that Steele et al. (2006) found that adding other spectral channels, in particular at shorter wavelengths, significantly decrease the uncertainties, leading to uncertainties $<2$ and $3 \%\left(r_{\mathrm{e}}\right.$ and $\left.c\right)$ when using the whole spectral range.

\section{Conclusions}

In this paper we have presented sensitivity analyses of the optical properties and BT signatures of secondary sulfate aerosols in the UTLS, based on TIR IASI pseudoobservations obtained with the $4 \mathrm{~A} / \mathrm{OP}$ radiative transfer model. We have modelled the sulfate aerosols as layers of $\mathrm{H}_{2} \mathrm{O} / \mathrm{H}_{2} \mathrm{SO}_{4}$ binary solution droplets with varying temperatures, mixing ratios and size distributions. The optical properties of these layers are obtained with a Mie code, taking as inputs the complex refractive indices of $\mathrm{H}_{2} \mathrm{O} / \mathrm{H}_{2} \mathrm{SO}_{4}$ binary solution with different temperatures and $\mathrm{H}_{2} \mathrm{SO}_{4}$ mixing ratios from laboratory measurements and archived in the GEISA database, and size distribution with different effective radii and effective number concentrations.

For these layers, we have determined characteristic BT spectral signatures in the spectral range $700-1200 \mathrm{~cm}^{-1}$, due to sulfate and bisulfate ions, and molecular undissociated $\mathrm{H}_{2} \mathrm{SO}_{4}$ absorption bands in the TIR. In this spectral region, a general decreasing BT signature (increasingly negative difference with respect to a no-aerosols baseline due to the increasing extinction coefficient) is observed. This signature is dominated by the stronger molecular $\mathrm{H}_{2} \mathrm{SO}_{4}$ absorption band at $1170 \mathrm{~cm}^{-1}$, which is particularly pronounced for realistic tropical UTLS conditions (low temperatures and $\mathrm{H}_{2} \mathrm{SO}_{4}$ mixing ratios greater than $60 \%$ ). The $\mathrm{BT}$ signature can reach values as high as $-5.0 \mathrm{~K}$ at $1170 \mathrm{~cm}^{-1}$, for big particles, and a high number concentration and $\mathrm{H}_{2} \mathrm{SO}_{4}$ mixing ratio. These conditions are typical of a volcanically perturbed UTLS. Another important feature that can modulate the shape of the BT sulfate aerosol signature is the $\mathrm{H}_{2} \mathrm{SO}_{4}$ absorption band at $905 \mathrm{~cm}^{-1}$. The extinction of the aerosol layer is found very weakly sensitive to the temperature of the droplets. The spectral extinction and then the BT signature is, at different extents, sensitive to the $\mathrm{H}_{2} \mathrm{SO}_{4}$ mixing ratio, the effective radius and number concentration. In general, the effective radius qualifies as the dominating factor determining the sensitivity of the sulfate aerosol extinction spectra and BT signatures. The main reason for the high sensitivity to the ef- 
Table 4. Total error (\%) for the retrieval of the three aerosol parameters: $N_{\mathrm{e}}, r_{\mathrm{e}}$ and $\mathrm{H}_{2} \mathrm{SO}_{4}$ mixing ratio, with different instrumental configurations (IASI HR refers to the IASI high spectral resolution; IASI BB refers to the IASI broadband features; MODIS BB refers to the MODIS broadband features; SEVIRI BB refers to the SEVIRI broadband features. See the text for further details). The error is calculated for typical background $(\mathrm{Bg})$ and volcanic (Volc) conditions.

\begin{tabular}{lrrrrrrrrrrrrr}
\hline & \multicolumn{3}{c}{ IASI HR } & \multicolumn{3}{c}{ IASI BB } & \multicolumn{3}{c}{ MODIS BB } & \multicolumn{3}{c}{ SEVIRI BB } \\
\hline & $N_{\mathrm{e}}$ & $r_{\mathrm{e}}$ & $c$ & $N_{\mathrm{e}}$ & $r_{\mathrm{e}}$ & $c$ & $N_{\mathrm{e}}$ & $r_{\mathrm{e}}$ & $c$ & $N_{\mathrm{e}}$ & $r_{\mathrm{e}}$ & $c$ \\
\hline $\mathrm{Bg}$ & $>100$ & 37.1 & 35.9 & $>100$ & $>100$ & 81.0 & $>100$ & $>100$ & $>100$ & $>100$ & $>100$ & $>100$ \\
Volc & 30.4 & 17.6 & 10.8 & 80.2 & 28.1 & 11.5 & 81.6 & 28.2 & 19.5 & 87.5 & 53.5 & 32.4 \\
\hline
\end{tabular}

fective radius is the related change in the effective mass of sulfates, even if a residual sensitivity to the effective radius is found for simulations at fixed mass. Sulfate aerosol layers in background conditions (small $\mathrm{H}_{2} \mathrm{SO}_{4}$ mixing ratios, and number concentrations and effective radii) seem not to be fully characterisable with IASI-like TIR instruments because of (1) small BT signatures, mainly due to the high sensitivity to the effective radius/mass, and (2) the interference of the $9.6 \mu \mathrm{m}$ ozone absorption band, which is superposed on the main sulfate/bisulfate ion absorption bands. Nevertheless, a residual information content is found in these pseudoobservations (about 1.3 DOF, and $>100,37.1$ and $35.9 \%$ uncertainties for the retrieval of $\left.\left[N_{\mathrm{e}}, r_{\mathrm{e}}, c\right]\right)$ in these conditions, meaning that a constrained retrieval of background sulfate aerosol properties is still feasible. BT spectral variability induced by the uncertainties on the vertical temperature profile and surface temperature is a further limiting factor for the observation of chemical and microphysical parameters of background sulfate aerosol layers in the UTLS. Other interfering species are identified, like sulfur dioxide, carbon dioxide, water vapour and ash. While carbon dioxide absorption bands are of limited concern in this context (stronger impact for wavenumbers lower than about $750 \mathrm{~cm}^{-1}$ ), attention must be paid to the sulfur dioxide absorption signature, which lies in the region of maximum sulfate BT signature, and the ubiquitous water vapour lines. The ash has a different BT signature than sulfates and its impact on the TOA radiances has a comparable magnitude to the volcanically enhanced sulfate aerosol layers. At the operational level, these interfering parameters should be retrieved simultaneously with sulfate aerosols or constrained with independent data.

From a remote sensing perspective, these analyses show that broadband features can be identified, like the maximum extinction at $1170 \mathrm{~cm}^{-1}(\mathrm{ME})$, its ratio with respect to the minimum extinction at $800 \mathrm{~cm}^{-1}$ (RE1) and the ratio of the secondary peak at $905 \mathrm{~cm}^{-1}$ with respect to the minimum extinction at $800 \mathrm{~cm}^{-1}$ (RE2). ME is sensitive to the $\mathrm{H}_{2} \mathrm{SO}_{4}$ mixing ratio, effective number concentration and radius, while RE1 and RE2 are only sensitive to the $\mathrm{H}_{2} \mathrm{SO}_{4}$ mixing ratio and the effective radius. While the information content carried by ME, RE1 and RE2 on the three aerosol parameters is partially independent for most conditions; (1) in background conditions, ME is scarcely sensitive to the effec- tive number concentration, and (2) in volcanically enhanced conditions, the variability of RE1 and RE2 with respect to the $\mathrm{H}_{2} \mathrm{SO}_{4}$ mixing ratio is very scarce, and the correlation of their information content is higher for higher $\mathrm{H}_{2} \mathrm{SO}_{4}$ mixing ratios. In addition, with this broadband approach, the three aerosol parameters are hardly retrievable as independent quantities and constraints should be given to at least one parameter. The analysis of the information content of broadband features approaches based on IASI (with a limited number of the full spectral resolution wavenumbers), MODIS and SEVIRI has shown that they are reasonably well adapted to characterise chemical and microphysical properties of sulfate aerosols in volcanic conditions $(2.41,2.11$ and $1.48 \mathrm{DOF}$ for IASI BB, MODIS BB and SEVIRI BB, with uncertainties of 28 (IASI BB) to $53 \%$ (SEVIRI BB) for the effective radius, 11 (IASI BB) to $32 \%$ (SEVIRI BB) for the mixing ratio and $>80 \%$ for the effective number concentration). Even if these broadband spectral features are appealing to quantitatively characterise sulfate aerosols, an important factor for a better characterisation is a fine spectral resolution. The benefits are twofold (1) in a broadband perspective, in order to accurately select spectral micro-windows representing ME, RE1 and RE2 or other equivalent spectral parameters (dedicated channels not always available in moderate resolution instruments, like MODIS or SEVIRI), and free from water vapour, sulfur dioxide and ozone interference; (2) in a high-spectralresolution spectral fitting perspective, to resolve the concurrent spectral absorption features of sulfates present in the aerosol droplets, and to precisely estimate the interfering parameters, as the temperature and humidity profile. The analysis of the information content of high-spectral-resolution (IASI HR) and broadband feature approaches has shown that the high resolution is a decisive factor for the characterisation of background sulfate aerosols (which are not observable with broadband features approaches). In volcanically enhanced conditions, IASI $\left[N_{\mathrm{e}}, r_{\mathrm{e}}, c\right]$ pseudo-observations, using the full spectral resolution, have 2.7 DOF, and 30.4, 17.6 and $10.8 \%$ retrieval uncertainties. A further significant added value is expected from the forthcoming new generation of satellite TIR instruments, including IASI-NG (New Generation) that will be launched in the 2020 time frame as part of the EPS-SG (EUMETSAT Polar System - Second 
Generation, formerly post-EPS) mission (Crevoisier et al., 2014).

\section{The Supplement related to this article is available online at doi:10.5194/amt-9-115-2016-supplement.}

Acknowledgements. The optical parameters of sulfate aerosol layers used in this work are obtained with the IDL Mie scattering routines developed by the Earth Observation Data Group of the Department of Physics of Oxford University, and available via the following website: http://eodg.atm.ox.ac.uk/MIE/. NOVELTIS is gratefully acknowledged for the support with the 4A/OP model. Alain Chédin, Virginie Capelle and Cyril Crevoisier are gratefully acknowledged for their help with 4A/OP, TIGR and the GEISA database. Hervé Herbin is gratefully acknowledge for the stimulating discussion during the last few years. The authors would like to thank the three anonymous referees for their constructive criticism; their contribution has been substantial towards the production of the final version of the present manuscript. This project has been partially supported by the EU 7th Framework Program under grant 603557 (StratoClim).

Edited by: F. Prata

\section{References}

Ackerman, S. A., and Strabala, K., I.: Satellite remote sensing of $\mathrm{H}_{2} \mathrm{SO}_{4}$ aerosol using the 8- to $12-\mu \mathrm{m}$ window region: Application to Mount Pinatubo, J. Geophys. Res., 99, 18639-18649, doi:10.1029/94JD01331, 1994.

Baran, A. J., Foot, J., S., and Dibben, P. C.: Satellite detection of volcanic sulphuric acid aerosol, J. Geophys. Res., 20, 17991801, doi:10.1029/93GL01965, 1993.

Barnes, W., Pagano, T., and Salomonson, V.: Prelaunch characteristics of the Moderate Resolution Imaging Spectroradiometer (MODIS) on EOS-AM1, IEEE T. Geosci. Remote, 36, 10881100, doi:10.1109/36.700993, 1998.

Bauman, J. J., Russell, P. B., Geller, M. A., and Hamill, P.: A stratospheric aerosol climatology from SAGE II and CLAES measurements: 1. Methodology, J. Geophys. Res.-Atmos., 108, 4382, doi:10.1029/2002JD002992, 2003.

Biermann, U. M., Luo, B. P., and Peter, T.: Absorption spectra and optical constants of binary and ternary solutions of $\mathrm{H}_{2} \mathrm{SO}_{4}$, $\mathrm{HNO}_{3}$, and $\mathrm{H}_{2} \mathrm{O}$ in the mid infrared at atmospheric temperatures, J. Phys. Chem.-US, 104, 783-793, doi:10.1021/jp992349i, 2000.

Boer, G. J., Sokolik, I. N., and Martin, S. T.: Infrared optical constants of aqueous sulfate-nitrate-ammonium multi-component tropospheric aerosols from attenuated total reflectance measurements: Part II. An examination of mixing rules, J. Quant. Spectrosc. Ra., 108, 39-53, doi:10.1016/j.jqsrt.2007.02.018, 2007.

Bourassa, A. E., Degenstein, D. A., Elash, B. J., and Llewellyn, E. J.: Evolution of the stratospheric aerosol enhancement following the eruptions of Okmok and Kasatochi: Odin-OSIRIS measurements, J. Geophys. Res.-Atmos., 115, D00L03, doi:10.1029/2009JD013274, 2010.
Chédin, A., Scott, N. A., Wahiche, C., and Moulinier, P.: Improved initialization inversion method: a high-resolution physical method for temperature retrievals from satellites of the TIROS-N series, J. Clim. Appl. Meteorol., 24, 128-143, 1985.

Chevallier, F., Chéruy, F., Scott, N. A., and Chédin, A.: A neural network approach for a fast and accurate computation of a longwave radiative budget, J. Appl. Meteorol., 37, 1385-1397, doi:10.1175/1520-0450(1998)037<1385:ANNAFA>2.0.CO;2, 1998.

Clarisse, L., Hurtmans, D., Prata, A. J., Karagulian, F., Clerbaux, C., Mazière, M. D., and Coheur, P.-F.: Retrieving radius, concentration, optical depth, and mass of different types of aerosols from high-resolution infrared nadir spectra, Appl. Optics, 49, 37133722, doi:10.1364/AO.49.003713, 2010.

Clarisse, L., Coheur, P.-F., Prata, F., Hadji-Lazaro, J., Hurtmans, D., and Clerbaux, C.: A unified approach to infrared aerosol remote sensing and type specification, Atmos. Chem. Phys., 13, 21952221, doi:10.5194/acp-13-2195-2013, 2013.

Corradini, S., Merucci, L., and Prata, A. J.: Retrieval of $\mathrm{SO}_{2}$ from thermal infrared satellite measurements: correction procedures for the effects of volcanic ash, Atmos. Meas. Tech., 2, 177-191, doi:10.5194/amt-2-177-2009, 2009.

Crevoisier, C., Clerbaux, C., Guidard, V., Phulpin, T., Armante, R., Barret, B., Camy-Peyret, C., Chaboureau, J.-P., Coheur, P.F., Crépeau, L., Dufour, G., Labonnote, L., Lavanant, L., HadjiLazaro, J., Herbin, H., Jacquinet-Husson, N., Payan, S., Péquignot, E., Pierangelo, C., Sellitto, P., and Stubenrauch, C.: Towards IASI-New Generation (IASI-NG): impact of improved spectral resolution and radiometric noise on the retrieval of thermodynamic, chemistry and climate variables, Atmos. Meas. Tech., 7, 4367-4385, doi:10.5194/amt-7-4367-2014, 2014.

Deshler, T., Hervig, M. E., Hofmann, D. J., Rosen, J. M., and Liley, J. B.: Thirty years of in situ stratospheric aerosol size distribution measurements from Laramie, Wyoming $\left(41^{\circ} \mathrm{N}\right)$, using balloon-borne instruments, J. Geophys. Res.-Atmos., 108, 4167, doi:10.1029/2002JD002514, 2003.

Doeringer, D., Eldering, A., Boone, C. D., González Abad, G., and Bernath, P. F.: Observation of sulfate aerosols and $\mathrm{SO}_{2}$ from the Sarychev volcanic eruption using data from the Atmospheric Chemistry Experiment (ACE), J. Geophys. Res.-Atmos., 117, D03203, doi:10.1029/2011JD016556, 2012.

Dubuisson, P., Herbin, H., Minvielle, F., Compiègne, M., Thieuleux, F., Parol, F., and Pelon, J.: Remote sensing of volcanic ash plumes from thermal infrared: a case study analysis from SEVIRI, MODIS and IASI instruments, Atmos. Meas. Tech., 7, 359-371, doi:10.5194/amt-7-359-2014, 2014.

Echle, G., von Clarmann, T., and Oelhaf, H.: Optical and microphysical parameters of the Mt. Pinatubo aerosol as determined from MIPAS-B mid-IR limb emission spectra, J. Geophys. Res.Atmos., 103, 19193-19211, doi:10.1029/98JD01363, 1998.

Eldering, A., Kahn, B. H., Mills, F. P., Irion, F. W., Steele, H. M., and Gunson, M. R.: Vertical profiles of aerosol volume from high spectral resolution infrared transmission measurements: results, J. Geophys. Res.-Atmos., 109, D20201, doi:10.1029/2004JD004623, 2004.

Gettelman, A., Liu, X., Barahona, D., Lohmann, U., and Chen, C.: Climate impacts of ice nucleation, J. Geophys. Res.-Atmos., 117, D20201, doi:10.1029/2012JD017950, 2012. 
Giguère, P. A. and Savoie, R.: Les spectres infrarouges de l'acide sulfuriques et des oléums, Can. J. Chemistry, 38, 24672476, doi:10.1139/v60-334, 1960.

Grainger, R. G., Lambert, A., Taylor, F. W., Remedios, J. J., Rodgers, C. D., Corney, M., and Kerridge, B. J.: Infrared absorption by volcanic stratospheric aerosols observed by ISAMS, Geophys. Res. Lett., 20, 1283-1286, doi:10.1029/93GL00823, 1993.

Griessbach, S., Hoffmann, L., Spang, R., von Hobe, M., Müller, R., and Riese, M.: Infrared limb emission measurements of aerosol in the troposphere and stratosphere, Atmos. Meas. Tech. Discuss., 8, 4379-4412, doi:10.5194/amtd-8-4379-2015, 2015.

Hamill, P., Jensen, E. J., Russell, P. B., and Bauman, J. J.: The life cycle of stratospheric aerosol particles, B. Am. Meteorol. Soc., 78, 1395-1410, doi:10.1175/15200477(1997)078<1395:TLCOSA>2.0.CO;2, 1997.

Jacquinet-Husson, N., Scott, N. A., Chedin, A., and Chursi, A. A.: The GEISA spectroscopic database system revisited for IASI direct radiative transfer modelling, Atmospheric and Oceanic Optics, 16, 256-282, 2003.

Jacquinet-Husson, N., Scott, N., Chédin, A., Crépeau, L., Armante, R., Capelle, V., Orphal, J., Coustenis, A., Boonne, C., Poulet-Crovisier, N., Barbe, A., Birk, M., Brown, L., CamyPeyret, C., Claveau, C., Chance, K., Christidis, N., Clerbaux, C., Coheur, P., Dana, V., Daumont, L., Backer-Barilly, M. D., Lonardo, G. D., Flaud, J., Goldman, A., Hamdouni, A., Hess, M., Hurley, M., Jacquemart, D., Kleiner, I., Köpke, P., Mandin, J., Massie, S., Mikhailenko, S., Nemtchinov, V., Nikitin, A., Newnham, D., Perrin, A., Perevalov, V., Pinnock, S., Régalia-Jarlot, L., Rinsland, C., Rublev, A., Schreier, F., Schult, L., Smith, K., Tashkun, S., Teffo, J., Toth, R., Tyuterev, V., Auwera, J. V., Varanasi, P., and Wagner, G.: The \{GEISA\} spectroscopic database: current and future archive for Earth and planetary atmosphere studies, J. Quant. Spectrosc. Ra., 109, 1043-1059, doi:10.1016/j.jqsrt.2007.12.015, 2008.

Karagulian, F., Clarisse, L., Clerbaux, C., Prata, A. J., Hurtmans, D., and Coheur, P. F., Detection of volcanic $\mathrm{SO}_{2}$, ash, and $\mathrm{H}_{2} \mathrm{SO}_{4}$ using the Infrared Atmospheric Sounding Interferometer (IASI), J. Geophys. Res., 115, D00L02, doi:10.1029/2009JD012786, 2010.

Kaufman, Y. J., Boucher, O., Tanré, D., Chin, M., Remer, L. A., and Takemura, T.: Aerosol anthropogenic component estimated from satellite data, Geophys. Res. Lett., 32, L17804, doi:10.1029/2005GL023125, 2005.

Knopf, D. A., Koop, T., Luo, B. P., Weers, U. G., and Peter, T.: Homogeneous nucleation of NAD and NAT in liquid stratospheric aerosols: insufficient to explain denitrification, Atmos. Chem. Phys., 2, 207-214, doi:10.5194/acp-2-207-2002, 2002.

Korolev, A. V., Isaac, G. A., Strapp, J. W., and Nevzorov, A. N.: In situ measurements of effective diameter and effective droplet number concentration, J. Geophys. Res.-Atmos., 104, 39934003, doi:10.1029/1998JD200071, 1999.

Lambert, A., R., Grainger, G., Rodgers, C. D., Taylor, F. W., Mergenthaler, J. L., Kumer, J. B., and Massie, S. T.: Global evolution of the Mt. Pinatubo volcanic aerosols observed by the infrared limb-sounding instruments CLAES and ISAMS on the Upper Atmosphere Research Satellite, J. Geophys. Res., 102, 1495-1512, doi:10.1029/96JD00096, 1997.
Lamsal, L. N., Weber, M., Tellmann, S., and Burrows, J. P.: Ozone column classified climatology of ozone and temperature profiles based on ozonesonde and satellite data, J. Geophys. Res.-Atmos., 109, D20304, doi:10.1029/2004JD004680, 2004.

McCormick, M. P., Thomason, L. W., and Trepte, C. R.: Atmospheric effects of the Mt Pinatubo eruption, Nature, 373, 399404, doi:10.1038/373399a0, 1995.

Miller, Y., Chaban, G. M., and Gerber, R. B.: Ab initio vibrational calculations for $\mathrm{H}_{2} \mathrm{SO}_{4}$ and $\mathrm{H}_{2} \mathrm{SO}_{4} \times \mathrm{H}_{2} \mathrm{O}$ : spectroscopy and the nature of the anharmonic couplings, J. Phys. Chem. A, 109, 6565-6574, doi:10.1021/jp0581101, 2005.

Pougatchev, N., August, T., Calbet, X., Hultberg, T., Oduleye, O., Schlüssel, P., Stiller, B., Germain, K. St., and Bingham, G.: IASI temperature and water vapor retrievals - error assessment and validation, Atmos. Chem. Phys., 9, 6453-6458, doi:10.5194/acp9-6453-2009, 2009.

Remer, L. A., Kaufman, Y. J., Tanré, D., Mattoo, S., Chu, D. A., Martins, J. V., Li, R.-R., Ichoku, C., Levy, R. C., Kleidman, R. G., Eck, T. F., Vermote, E., and Holben, B. N.: The MODIS aerosol algorithm, products, and validation, J. Atmos. Sci., 62, 947-973, doi:10.1175/JAS3385.1, 2005.

Robock, A. and Oppenheimer, C.: Volcanism and the Earth's Atmosphere, vol. 139 of Geophysical Monograph Series, American Geophysical Union, Washington, DC, USA, 187-236, 2003.

Rodgers, C. D.: Inverse Methods for Atmospheric Sounding: Theory and Practice, vol. 2 of Series on Atmospheric Oceanic and Planetary Physics, World Scientific, London, UK, 43-64, 2000.

Scott, N. A. and Chedin, A.: A fast line-by-line method for atmospheric absorption computations: the automatized atmospheric absorption atlas, J. Appl. Meteorol., 20, 802-812, doi:10.1175/1520-0450(1981)020<0802:AFLBLM>2.0.CO;2, 1981.

Sheng, J.-X., Weisenstein, D. K., Luo, B.-P., Rozanov, E., Stenke, A., Anet, J., Bingemer, H., and Peter, T.: Global atmospheric sulfur budget under volcanically quiescent conditions: aerosol-chemistry-climate model predictions and validation, J. Geophys. Res.-Atmos., 120, 256-276, doi:10.1002/2014JD021985, 2015.

SPARC: Assessment of Stratospheric Aerosol Properties, edited by: Thomason, L. and Peter. T., WCRP-124 WMO/TD-No. 1295, 4, 2006.

Steele, H. M., Eldering, A., and Lumpe, J., D., Simulations of the accuracy in retrieving stratospheric aerosol effective radius, composition, and loading from infrared spectral transmission measurements, Appl. Opt., 45, 2014-2027, doi:10.1364/AO.45.002014, 2006.

Thomason, L. W., Poole, L. R., and Deshler, T.: A global climatology of stratospheric aerosol surface area density deduced from Stratospheric Aerosol and Gas Experiment II measurements: 1984-1994, J. Geophys. Res.-Atmos., 102, 8967-8976, doi:10.1029/96JD02962, doi:10.1029/96JD02962, 1997.

Tjemkes, S., Patterson, T., Rizzi, R., Shephard, M., Clough, S., Matricardi, M., Haigh, J., Höpfner, M., Payan, S., Trotsenko, A., Scott, N., Rayer, P., Taylor, J., Clerbaux, C., Strow, L., DeSouzaMachado, S., Tobin, D., and Knuteson, R.: The \{ISSWG $\}$ lineby-line inter-comparison experiment, J. Quant. Spectrosc. Ra., 77, 433-453, doi:10.1016/S0022-4073(02)00174-7, 2003.

Tournier, B., Blumstein, D., and Cayla, F. R.: IASI level 0 and 1 processing algorithms description, in: Proc. 12th Interna- 
tional TOVS Working Group, Lorne, Australia, available at: https://cimss.ssec.wisc.edu/itwg/itsc/itsc12/presentations/6d5_

B.Tournier.doc (last access: 11 January 2016), 2002.

van de Hulst, H.: Light Scattering by Small Particles, Dover Books on Physics Series, Dover Publications, Mineola, New York, USA, available at: http://books.google.fr/books?id= PIHfPMVAFRcC (last access: 7 August 2015), 1957.

von Glasow, R., Bobrowski, N., and Kern, C.: The effects of volcanic eruptions on atmospheric chemistry, Chem. Geol., 263, 131-142, doi:10.1016/j.chemgeo.2008.08.020, 2009.

Wan, Z.: Estimate of noise and systematic error in early thermal infrared data of the Moderate Resolution Imaging Spectroradiometer (MODIS), Remote Sens. Environ., 80, 47-54, doi:S00344257(01)00266-8, 2002.
Yu, T., and Rose, W. I.: Retrieval of Sulfate and Silicate Ash Masses in Young ( 1 to 4 Days Old) Eruption Clouds Using Multiband Infrared HIRS/2 Data, in: Remote Sensing of Active Volcanism, edited by: Mouginis-Mark, P. J., Crisp, J. A. and Fink, J. H., American Geophysical Union, Washington, DC, doi:10.1029/GM116p0087, 87-100, 2000.

Yu, P., Toon, O. B., Neely, R. R., Martinsson, B. G., and Brenninkmeijer, C. A. M.: Composition and physical properties of the Asian Tropopause Aerosol Layer and the North American Tropospheric Aerosol Layer, Geophys. Res. Lett., 42, 25402546, doi:10.1002/2015GL063181, 2015. 